\title{
Evaluating Mitigation Effort: Tools and Institutions for Assessing Nationally Determined Contributions
}

\section{Citation}

Aldy, Joseph E. 2015. Evaluating Mitigation Effort: Tools and Institutions for Assessing Nationally Determined Contributions. Cambridge, Mass.: Harvard Project on Climate Agreements, Belfer Center for Science and International Affairs, Harvard Kennedy School.

\section{Published Version}

http://belfercenter.ksg.harvard.edu/files/evaluating-mitigation-effort-aldy_web.pdf

\section{Permanent link}

http://nrs.harvard.edu/urn-3:HUL.InstRepos:23936083

\section{Terms of Use}

This article was downloaded from Harvard University's DASH repository, and is made available under the terms and conditions applicable to Other Posted Material, as set forth at http:// nrs.harvard.edu/urn-3:HUL.InstRepos:dash.current.terms-of-use\#LAA

\section{Share Your Story}

The Harvard community has made this article openly available.

Please share how this access benefits you. Submit a story.

Accessibility 


\section{Evaluating Mitigation Effort:}

Tools and Institutions for Assessing Nationally Determined Contributions

Joseph E. Aldy

Harvard Kennedy School
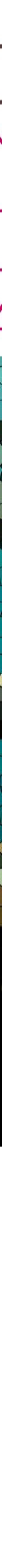
World Bank Group's Networked Carbon Markets Initiative 



\title{
Evaluating Mitigation Effort: Tools and Institutions for Assessing Nationally Determined Contributions
}

\author{
Joseph E. Aldy \\ Harvard Kennedy School
}

November 2015 


\section{THE HARVARD PROJECT ON CLIMATE AGREEMENTS}

The goal of the Harvard Project on Climate Agreements is to help identify and advance scientifically sound, economically rational, and politically pragmatic public policy options for addressing global climate change. Drawing upon leading thinkers in Argentina, Australia, China, Europe, India, Japan, and the United States, the Project conducts research on policy architecture, key design elements, and institutional dimensions of domestic climate policy and a post-2015 international climate policy regime. The Project is directed by Robert N. Stavins, Albert Pratt Professor of Business and Government, Harvard Kennedy School. For more information, see the Project's website: http://belfercenter.ksg.harvard.edu/climate.

\section{ACKNOWLEDGEMENTS}

The Harvard Project on Climate Agreements is grateful for support from and collaboration with the following organizations, in the preparation of this paper: Enel Foundation, International Emissions Trading Association, and World Bank Group's Networked Carbon Markets Initiative.

The Harvard Project on Climate Agreements also receives support from the Belfer Center for Science and International Affairs and the Hui Research Fund for Generating Powerful Ideas at the Ash Center for Democratic Governance and Innovation-both located at the Harvard Kennedy School; the Harvard University Center for the Environment; and Christopher P. Kaneb (Harvard AB 1990).

The closely affiliated, University-wide Harvard Environmental Economics Program receives additional support from the Enel Endowment for Environmental Economics at Harvard University, the Alfred P. Sloan Foundation, the Mossavar-Rahmani Center for Business and Government at the Harvard Kennedy School, Bank of America, BP, Castleton Commodities International LLC, Chevron Services Company, Duke Energy Corporation, and Shell.

\section{CITATION INFORMATION}

Aldy, Joseph E. "Evaluating Mitigation Effort: Tools and Institutions for Assessing Nationally Determined Contributions." Cambridge, Mass.: Harvard Project on Climate Agreements, November 2015.

The views expressed in Harvard Project on Climate Agreements publications are those of the author(s) and do not necessarily reflect those of the Harvard Kennedy School or of Harvard University. Discussion Papers have not undergone formal review and approval. Such papers are intended to elicit feedback and to encourage debate on important public policy challenges. Copyright belongs to the author(s). Papers may be downloaded for personal use only. 


\title{
Evaluating Mitigation Effort: Tools and Institutions for Assessing Nationally Determined Contributions
}

\author{
Joseph E. Aldy* \\ Harvard Project on Climate Agreements
}

\begin{abstract}
SUMMARY
The emerging pledge and review approach to international climate policy provides countries with substantial discretion in how they craft their intended emission mitigation contributions. The resulting heterogeneity in mitigation pledges creates a significant demand for a wellfunctioning transparency and review mechanism. In particular, the specific forms of intended contributions necessitate economic analysis in order to estimate the aggregate effects of these contributions, as well as to permit "apples-to-apples" comparisons of mitigation efforts. This paper discusses the tools that can inform such analyses, as well as the institutional framework needed to support climate transparency. In light of the negotiating challenges with respect to transparency, the paper describes the potential for countries to implement Living Mitigation Plans that include regular updating of domestic mitigation programs with data and analyses on their outcomes. Such Living Mitigation Plans can serve as the foundation for independent, expert review of domestic mitigation programs. Moreover, they can include the inputs necessary to assess the mitigation value of domestic mitigation efforts. Such assessments could inform the linkage of domestic mitigation policies, especially among disparately designed mitigation policies.
\end{abstract}

\footnotetext{
* The author is also affiliated with Resources for the Future, National Bureau of Economic Research, and Center for Strategic and International Studies. Contact: joseph_aldy@hks.harvard.edu; Harvard Kennedy School, 79 John F. Kennedy Street, Mailbox 114, Cambridge, Massachusetts, USA 02138. This work has been supported by the Enel Foundation, the International Emissions Trading Association, and the World Bank Group. Daniele Agostini, Irina Lazzerini, Giuseppe Montesano, Mariano Morazzo, Robert Stavins, Robert Stowe, Jeff Swartz, Bianca Sylvester, Marika Tatsutani, and participants in the Harvard Project on Climate Agreements May 2015 workshop on comparison and linkage of mitigation efforts provided excellent comments on earlier drafts of this work. For more on the workshop, including most presentations, see: http://belfercenter. ksg.harvard.edu/publication/25401. The author is grateful to Bryan Galcik for layout and design of the paper.
}

HARVARD PROJECT ON CLIMATE AGREEMENTS • HARVARD KENNEDY SCHOOL " III 


\section{TABLE OF CONTENTS}

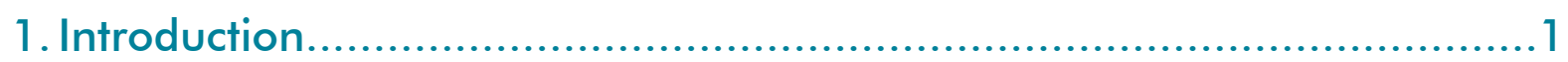

2. The Need for Evaluation Tools.....................................................

3. Tools for Assessing Effort..............................................................8

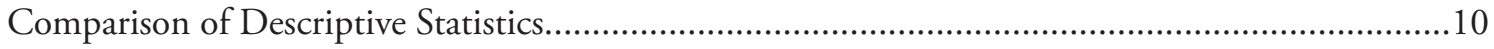

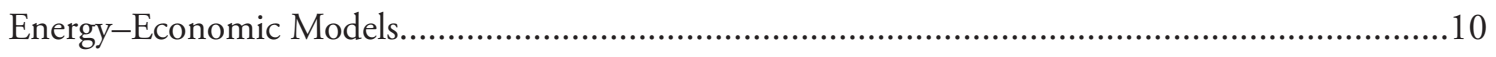

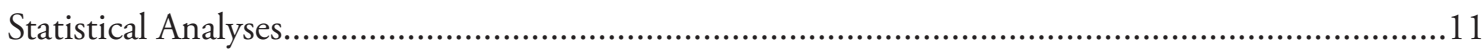

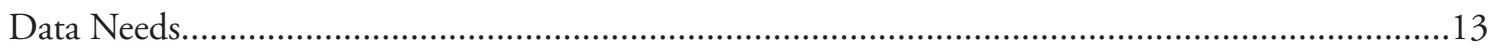

4. Institutions for Applying, Testing, and Evaluating Tools: The Role of Transparency.................................................................... 13

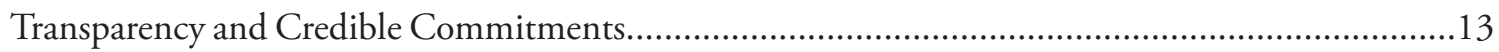

Transparency Models from Other Multilateral Regimes.................................................................15

Lessons from Other Multilateral Regimes' Transparency Models..................................................18

5. Using Mitigation Assessments to Support an International Agreement.........................................................................22

Transparency Raises Costs of Deviating from Pledges..............................................................22

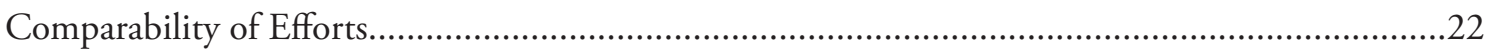

Implications for Border Tax Adjustments...........................................................................23

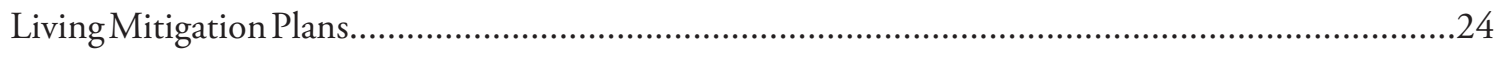

6. Using Mitigation Assessments to Facilitate Linkage...........................29

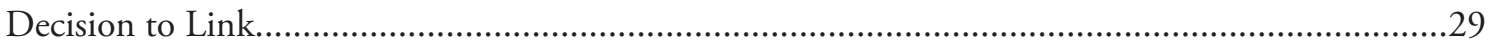

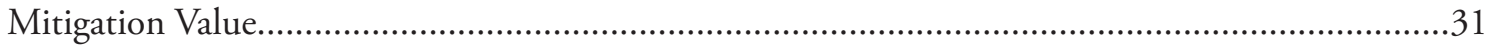

Mitigation Value, Transparency, and Living Mitigation Plans........................................................33

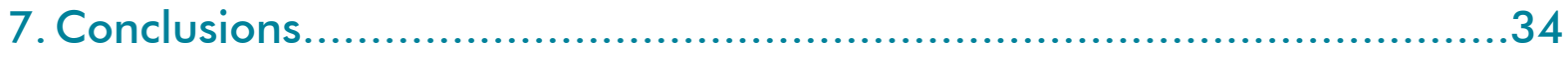

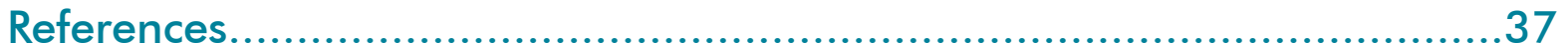




\section{INTRODUCTION}

A pledge and review approach to emission mitigation has emerged in international climate policy architecture since the 2009 climate negotiations in Copenhagen (Aldy and Stavins 2012). Over 80 developed and developing countries "inscribed" their independently-developed mitigation targets, goals, and policies in the 2009 Copenhagen Accord ${ }^{1}$ and the 2010 Cancun Agreements, ${ }^{2}$ negotiated under the aegis of the United Nations Framework Convention on Climate Change (UNFCCC). The 2014 Lima Call for Climate Action ${ }^{3}$ invited countries to voluntarily submit their intended nationally determined contributions (INDCs) to the post2020 emission mitigation efforts. A major new agreement structuring the post-2020 climate regime will likely be concluded at the annual UNFCCC conference in Paris in December $2015 . .^{4}$

Given the discretion left with national governments on the form and timing of their mitigation contributions under the Paris agreement, this pledge and review approach creates a significant demand for a well-functioning transparency regime (Aldy 2014b). Determining INDCs' emission impacts and environmental benefits requires sophisticated evaluation (Aldy and Pizer 2015). A system of voluntary mitigation pledges will generate interest among stakeholders in methods to compare intended contributions. For example, assessments of INDCs' emission impacts may enable environmental stakeholders to identify less ambitious countries and to pressure them to enhance their mitigation ambition. The relative energy-price and economiccost impacts of INDCs may draw the attention of business stakeholders, who may be concerned about the competitiveness impacts of climate policy. Domestic political pressures will drive interest in transparency, assessment, and comparability of mitigation efforts.

The dramatic heterogeneity in the INDCs submitted to date creates a significant need for rigorous tools for evaluation.

Moreover, assessments of domestic mitigation programs can help countries identify potential partners with whom they could link their domestic mitigation efforts (Bodansky et al. 2014). This could take the form of linking two cap-and-trade programs, or perhaps finding ways of linking two disparate means of implementation (Metcalf and Weisbach 2012). The latter, especially, would benefit from a rigorous assessment of mitigation activities to ensure that linking does not undermine the environmental benefits of domestic programs designed to implement the countries' respective INDCs.

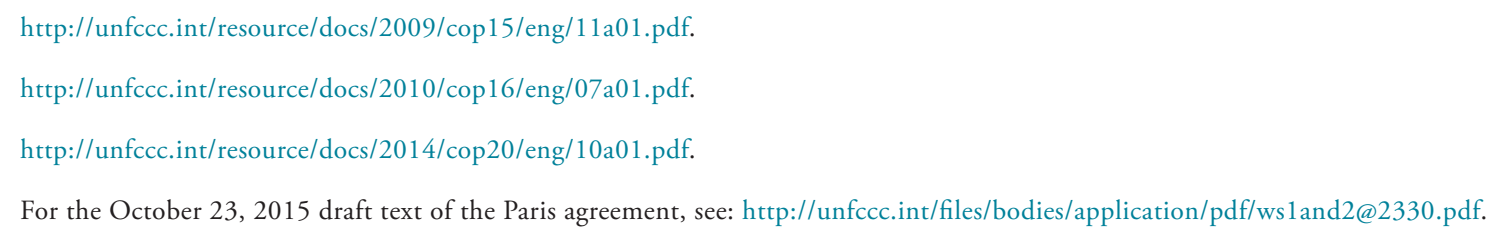


The dramatic heterogeneity in the INDCs submitted to date creates a significant need for rigorous tools for evaluation. First, an assessment of the aggregate emission impact of the INDCs requires economic and related analysis to convert a number of the forms of contributions - including emission peak years, reductions in the emission-to-GDP ratio, and reductions from a forecast business-as-usual emission level - into an emissions-level metric. Second, an "apples-to-apples" comparison of contributions from these disparate formats would also require economic and/or statistical analyses (Aldy and Pizer 2015).

In order to assess and compare contributions, analysts may draw from an array of tools. The choice of tool will depend on the policy question under consideration. Some simple analysis of INDCs may be sufficient to generate an estimate of emissions impacts. More sophisticated tools may be necessary, however, to assess economic costs and carbon and energy prices, as well as potential trade effects.

Conducting assessments of countries' domestic policy programs places substantial institutional demands on the multilateral climate negotiations. A long literature in international relations and law highlights the importance of designing legitimate, professional institutions for policy surveillance (Thompson 2006a; Victor 2007; Hafner-Burton et al. 2012; Aldy 2014b). Lessons from the implementation of policy surveillance in other multilateral contexts can help inform the design of a rigorous climate-policy-surveillance regime that can enable assessments and comparisons of mitigation efforts. Integrating these independent efforts with countries' own domestic review and surveillance programs can further enhance the transparency and hence credibility of the pledge and review approach to climate policy. To illustrate a way in which domestic mitigation efforts can contribute to this transparency, I describe below an approach that I refer to as "Living Mitigation Plans."

Mitigation assessment can also play an important role in enabling the linking of domestic mitigation programs. Such assessments can address questions from domestic stakeholders about the economic and environmental implications of potentially linking with another domestic mitigation program. In the specific case of linking two disparate domestic mitigation programs - such as cap and trade in one country with a carbon tax in another, or cap and trade in one country and a performance regulation in another - analysts may want to employ tools that can characterize both the environmental and economic impacts associated with the linkage, as well as ways of assessing the mitigation value of the domestic programs without a hard emissions cap (Lazarus et al. 2015; Marcu 2014, 2015; World Bank 2015).

The next section of the paper will examine in more detail the need for evaluation and assessment tools. Section three presents some of the tools that could be employed for assessments and discusses how the nature of the policy question will frame the appropriateness of any given tool. The fourth section illustrates institutional approaches for applying, testing, and evaluating 
these tools for assessment, with attention to the importance of transparency. The fifth section describes how mitigation assessments would enable the "review" in "pledge and review" to support an international agreement, with a detailed discussion of enhancing countries' own roles through Living Mitigation Plans. The sixth section addresses how mitigation assessments could facilitate linkage of domestic mitigation programs. The final section concludes.

\section{THE NEED FOR EVALUATION TOOLS}

The pledge and review approach represented by countries tabling their INDCs requires rigorous evaluation tools. Each INDC describes that country's mitigation objective and, to some extent, its emission mitigation program. The Lima Call for Climate Action provided substantial discretion to countries in how they craft their intended contributions.

As a result, there is significant heterogeneity in the forms of mitigation contributions in the 129 INDCs submitted to the climate negotiations through November 8, 2015. While most industrialized countries have focused on economy-wide greenhouse gas emission targets, they differ in their choice of base years and target years. For example, the European Union, Norway, Russia, Switzerland, and other countries characterize their contributions as percentage reductions relative to a 1990 base year, while Australia, Canada, Japan, New Zealand, and the United States have employed a 2005 base year. The United States' INDC calls for reducing emissions through 2025, but other industrialized countries' contributions are set through 2030. Some of these industrialized countries' INDCs explicitly acknowledge the use of international trading and offset mechanisms (e.g., Switzerland, New Zealand, and South Korea), while others explicitly rule out international market mechanisms (e.g., the United States).

There is even more variation among developing countries' INDCs. The heterogeneity among these countries mirrors the heterogeneity in the inscribed mitigation policies and goals in the 2009 Copenhagen Accord and 2010 Cancun Agreements. Some countries have established target years by which their carbon dioxide or greenhouse gas emissions will peak, including China (2030), Singapore (2030), and South Africa (2025). A large number of countries intend to reduce their emissions relative to a forecast business-as-usual level for the year 2030, such as Algeria, Argentina, Colombia, Indonesia, Mexico, the Philippines, South Korea, Thailand, Turkey, and Vietnam. Another set of countries plans to reduce emission intensity, measured as the ratio of carbon dioxide emissions to gross domestic product (GDP), including Chile, China, India, and Tunisia.

The INDCs are available on the UNFCCC web site: http://www4.unfccc.int/submissions/INDC/Submission\%20Pages/ submissions.aspx. See also World Resources Institute Climate Analysis Indicators Tool (WRI CAIT): http://cait.wri.org/indc. The 129 INDCs represent 157 parties to the UNFCCC, including the 28 individual member states of the European Union, out of 196 total UNFCCC parties. 
Several contributions include multiple forms of policy goals. China's INDC includes an emission peak year, a reduction in carbon intensity, and a non-fossil-fuel share of primary energy consumption. Singapore's INDC puts forward an intensity target and a peak year. Many developing countries have included a dual set of contributions, one unconditional and one conditional on external financing, including Bangladesh, Benin, Burundi, Chad, Ecuador, Jordan, Lebanon, the Maldives, Morocco, Peru, Trinidad and Tobago, and Togo. (See Figure 1 for a map illustrating the range of submitted INDCs.) ${ }^{6}$

\section{Figure 1: Submitted INDCS}

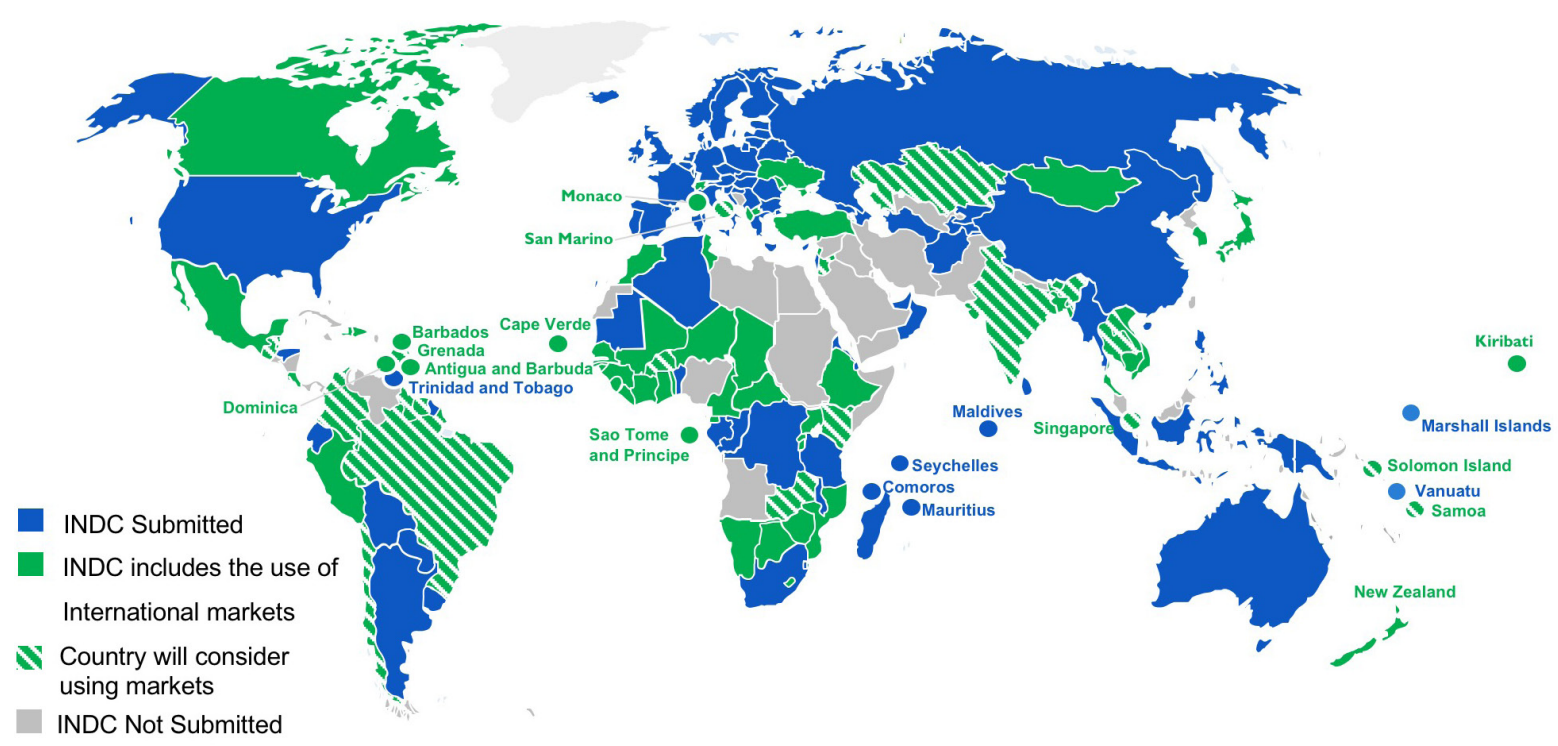

Credit: International Emissions Trading Association

This heterogeneity is a natural outgrowth of the voluntary pledge and review regime. By permitting countries to design their own domestic mitigation contributions, they can tailor their emission mitigation goals and policies to their national economic, institutional, and political circumstances. This enables broader participation with regard to emission mitigation in the current multilateral climate policy framework than in previous agreements. The Kyoto Protocol's first commitment period established targets for 38 nations representing 51\% of 
global greenhouse gas emissions in 1997. At the 2012 UNFCCC climate talks in Doha, 31 countries representing $12 \%$ of 2012 global greenhouse gas emissions decided to participate in the second commitment period of the Kyoto Protocol. By contrast, the 2009 Copenhagen Accord, the initial foray into a pledge and review framework and the precursor to the current approach, included voluntary emission mitigation commitments through 2020 from more than 80 countries representing more than $80 \%$ of 2009 global greenhouse gas emissions. An almost identical set of commitments was associated with the 2010 Cancun Agreements.

This voluntary pledging approach, however, creates several challenges for evaluating the individual and collective impact of the pledges.

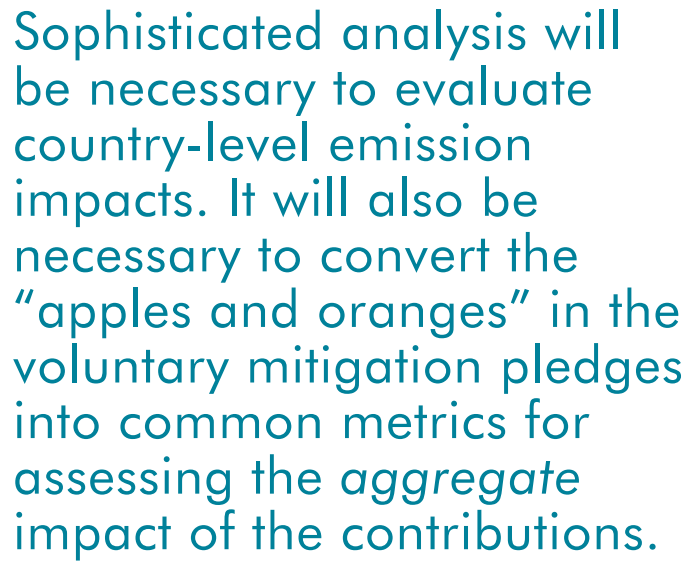
Under the Kyoto Protocol, all country targets were percentage reductions from a 1990 base year level of emissions, ${ }^{8}$ and the industrialized countries had an aggregate target to reduce emissions at least 5\% below 1990 levels derived from these country targets. In contrast to this uniform approach, the heterogeneity in contributions under the emerging regime does not simply and transparently yield an estimate of aggregate mitigation effort.

Economic modeling tools are necessary to generate estimates of emissions levels under contributions specified as reductions in carbon intensity, emissions peaking by a specified year, or emission reductions from forecast business-as-usual contributions (Aldy and Pizer 2015). Moreover, the emission impacts of an individual country's contribution in the emission intensity reduction and peak year categories will depend on the breadth and stringency of other countries' mitigation pledges. Economic tools can account for how global markets generally, and especially markets for fossil fuels, respond to the expected implementation of INDCs, which in turn could affect economic growth, the carbon intensity of economic growth, and the timing of emissions peaking in these countries.

The key point is that sophisticated analysis will be necessary to evaluate country-level emission impacts. It will also be necessary to convert the "apples and oranges" in the voluntary mitigation pledges into common metrics for assessing the aggregate impact of the contributions - such

\footnotetext{
7 All references to global greenhouse gas emissions in this paragraph are from WRI CAIT: http://cait.wri.org (land use changes excluded). Pledges for mitigation effort through 2020 (inscribed in the Copenhagen Accord and Cancun Agreements or submitted subsequently) are listed, with links to the text of the pledges, on WRI CAIT: http://cait.wri.org/pledges. See also interactive map of pre-2020 pledges on the UNFCCC's web site: http://unfccc.int/2860.php. 
as future aggregate emission levels or costs - which in turn can feed into climate-modeling analyses of temperature and related climate change impacts. ${ }^{?}$

The development and use of tools to evaluate INDCs is in part motivated by domestic and international interest in comparing mitigation effort among countries. First, the domestic political implications of a country pledging to mitigate its emissions may drive demand for transparency and assessments of comparability of effort. Environmental stakeholders may use assessments of individual countries' mitigation contributions to apply pressure for more ambitious action. Comparative assessments could enable environmental stakeholders to lobby their government to undertake more mitigation to match the ambition of its peers. These assessments may also enable environmental stakeholders to defend, to their peers, the pledges of those countries taking on comparable effort.

In addition, business stakeholders, especially those whose products face international competition, may have substantial interests in ensuring that their country's mitigation contribution will not put them at a competitive disadvantage relative to similar businesses in other countries. Assessments of comparability of effort could inform specific policy mechanisms intended to address potentially adverse competitiveness impacts from domestic emission mitigation policies, such as free, output-based allocation of emission allowances in cap-and-trade programs and border tax adjustments on imports in carbon tax regimes (Aldy 2015a; Aldy and Pizer 2014).

Second, countries typically agree voluntarily to multilateral coordination if they believe they are getting a "fair deal." What constitutes a fair deal may vary from country to country, depending on the preferences of leaders, stakeholders, and publics. Regardless of a country's perspective, however, most notions of fairness involve some consideration of (and thus a need for assessing) relative contributions. Indeed, the UNFCCC's principle of "common but differentiated responsibilities and respective capabilities" recognizes that contributions have a common element as well as a differentiated element, and implementing this principle in practice requires an assessment and comparison of mitigation effort.

Some analysts have also advocated approaches to setting country emission targets that reflect various notions of equity (e.g., Bosetti and Frankel 2012; den Elzen et al. 2006; Gupta 2007; Hof and den Elzen 2010; Michaelowa et al. 2005). While the current voluntary pledging regime is inconsistent with a top-down, equity-rule or formulaic approach to setting targets, some may use such analyses as a benchmark for evaluating the fairness of the voluntary pledges.

The member countries of the UNFCCC, in Lima in late 2014, directed the Convention's Secretariat to produce a report by November 1, 2015 "on the aggregate effect [on emissions] of the intended nationally determined contributions (INDCs) communicated by Parties." The mandate specified that only INDCs submitted by October 1, 2015 be included. The report may be found at: http:// unfccc.int/resource/docs/2015/cop21/eng/07.pdf. "Key challenges and assumptions" are discussed in Section C.3, pp. 23-26. 
When most large emitters perceive the climate-change regime as fair, there is at least the possibility of countries and groups of countries increasing their mitigation contributions over time.

Third, assessing and comparing mitigation effort in countries' contributions can highlight similarities or differences in the expected marginal cost of emission abatement. Significant variation in these marginal costs would suggest that the emerging architecture is not cost-effective. This has important long-term implications; Bodansky et al. (2014) and Ranson and Stavins (2013) emphasize the role that minimizing the costs of mitigating emissions can have in leveraging more ambitious mitigation goals and efforts over time. The increased transparency of domestic planning processes and expected implementation programs can facilitate analyses of expected mitigation costs. Substantial differences in expected marginal abatement costs, while revealing potentially large benefits from coordinating on mitigation policies and convergence in the shadow price on a ton of carbon, may reflect domestic and international political economy concerns. The latter, as a function of equity concerns, could yield wealthy countries with higher marginal abatement costs than lower-income countries. The former, due to domestic political opposition to large transfers from developed countries to developing countries, could hinder the prospect for efforts to coordinate policies.

The most natural way for two countries to coordinate their policy efforts - and realize the cost-savings of convergence in the shadow price of carbon - is by linkage of their domestic programs. Assessment and comparison of effort can serve to highlight the potential gains from trade in bilateral linkage and, by reducing costs, may further prompt increased ambition over time. Moreover, assessment of a country's INDC and domestic mitigation program can provide assurances about the environmental integrity - such as through its domestic policy surveillance and compliance mechanisms - of a partner country's policies, so that efforts to promote cost-effectiveness do not subsequently undermine the environmental benefits of (and hence the political support for) linking (Bodansky et al. 2014; Lazarus et al. 2015; World Bank 2015). These issues will be discussed in more detail below. 


\section{Figure 2: Why Compare Effort?}

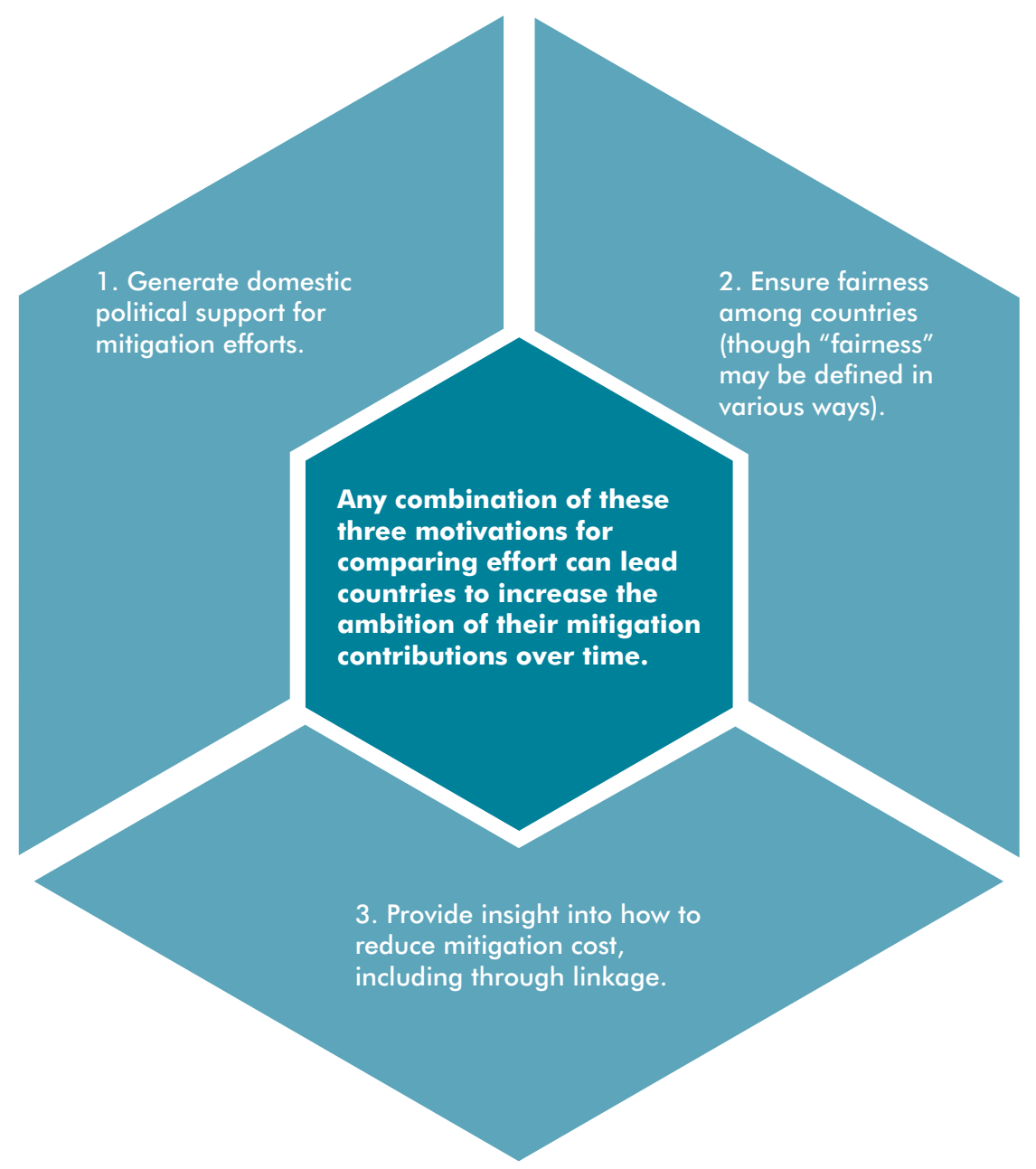

\section{TOOLS FOR ASSESSING EFFORT}

Aldy and Pizer (2015) describe four principles that might motivate the choice of metrics for mitigation effort - and comparison of effort across countries. First, an ideal metric would comprehensively represent the entire mitigation effort of a country. Second, metrics should be observable, measurable, and quantitative. Third, metrics should be replicable by independent third parties, to ensure the legitimacy of the metrics. Finally, metrics should be universally applied among countries participating in global climate policy. Possibilities range from emissions metrics (emissions levels, emission intensities, and emission reductions from business as usual), price metrics (such as carbon and energy prices), and cost metrics (such as mitigation costs). Aldy, Pizer, and Akimoto (2015) conclude that no single metric is ideal, and thus recommend using a suite of metrics for comparing effort, just as an analyst would rely on a suite of economic indicators for characterizing the health of the macroeconomy. See Table 1 for further detail. 


\section{Table 1: Synthesis of Metrics for and Principles of Comparison of Mitigation Effort}

\begin{tabular}{|c|c|c|c|c|}
\hline & \multicolumn{4}{|c|}{ Principle } \\
\hline Metric & Comprehensive & Measurable & Replicable & Universal \\
\hline $\begin{array}{l}\text { Emission } \\
\text { Levels }\end{array}$ & $\begin{array}{l}\text { A poor estimate } \\
\text { of effort because it } \\
\text { conflates natural } \\
\text { trends }\end{array}$ & Yes & $\begin{array}{l}\text { Yes; public domain } \\
\text { data for energy and } \\
\text { fossil } \mathrm{CO}_{2} \text { available }\end{array}$ & $\begin{array}{l}\text { Fossil } \mathrm{CO}_{2} \text { data exist } \\
\text { for all countries; } \\
\text { additional work needed } \\
\text { for all GHGs }\end{array}$ \\
\hline $\begin{array}{l}\text { Emission } \\
\text { Intensities }\end{array}$ & $\begin{array}{l}\text { Better than } \\
\text { emission levels } \\
\text { as it controls for } \\
\text { economic trends, } \\
\text { but a noisy signal }\end{array}$ & Yes & $\begin{array}{l}\text { Yes; public domain } \\
\text { data for energy and } \\
\text { fossil } \mathrm{CO}_{2} \text { available }\end{array}$ & $\begin{array}{l}\text { Yes for fossil } \mathrm{CO}_{2} / \\
\text { GDP; additional work } \\
\text { needed for GHG/GDP }\end{array}$ \\
\hline $\begin{array}{l}\text { Emission } \\
\text { Abatement }\end{array}$ & $\begin{array}{l}\text { Most } \\
\text { comprehensive } \\
\text { among emission- } \\
\text { related metrics }\end{array}$ & $\begin{array}{l}\text { Challenging } \\
\text { - requires } \\
\text { modeling tools / } \\
\text { subjective choices } \\
\text { to determine } \\
\text { counterfactuals }\end{array}$ & $\begin{array}{l}\text { Different model } \\
\text { structures with } \\
\text { different assumptions } \\
\text { could yield different } \\
\text { outcomes }\end{array}$ & $\begin{array}{l}\text { No, few modeling } \\
\text { platforms evaluate more } \\
\text { than }-10 \text { countries }\end{array}$ \\
\hline $\begin{array}{l}\text { Carbon } \\
\text { Prices }\end{array}$ & $\begin{array}{l}\text { Captures effort per } \\
\text { ton, but says little } \\
\text { about tons }\end{array}$ & $\begin{array}{l}\text { Explicit, yes; } \\
\text { implicit requires } \\
\text { detailed analyses }\end{array}$ & $\begin{array}{l}\text { Yes for explicit prices; } \\
\text { implicit prices may } \\
\text { depend on analytic } \\
\text { assumptions }\end{array}$ & $\begin{array}{l}\text { No, given few explicit } \\
\text { carbon pricing policies; } \\
\text { modeling tools } \\
\text { necessary to estimate } \\
\text { implicit carbon prices }\end{array}$ \\
\hline $\begin{array}{l}\text { Energy } \\
\text { Prices and } \\
\text { Taxes }\end{array}$ & $\begin{array}{l}\text { Inadequate for } \\
\text { non-energy } \\
\text { emissions; fails to } \\
\text { account for non- } \\
\text { market regulatory } \\
\text { instruments }\end{array}$ & $\begin{array}{l}\text { Yes, but unclear } \\
\text { how to aggregate }\end{array}$ & Yes & $\begin{array}{l}\text { Yes, but requires more } \\
\text { detailed data collection } \\
\text { than currently in public } \\
\text { domain }\end{array}$ \\
\hline $\begin{array}{l}\text { Abatement } \\
\text { Costs }\end{array}$ & $\begin{array}{l}\text { Best measure of } \\
\text { effort, still requires } \\
\text { benchmarking }\end{array}$ & $\begin{array}{l}\text { Challenging } \\
\text { - requires } \\
\text { modeling tools / } \\
\text { subjective choices } \\
\text { to determine } \\
\text { counterfactuals and } \\
\text { model costs }\end{array}$ & $\begin{array}{l}\text { Different model } \\
\text { structures with } \\
\text { different assumptions } \\
\text { could yield different } \\
\text { outcomes }\end{array}$ & $\begin{array}{l}\text { No, few modeling } \\
\text { platforms to } \\
\text { comprehensively } \\
\text { evaluate more than }-10 \\
\text { countries }\end{array}$ \\
\hline
\end{tabular}

Source: Aldy and Pizer 2015. 
In the context of the UNFCCC negotiations and the Paris agreement, the choice among metrics depends in large part upon the type of mitigation objectives countries choose in their INDCs. However the choice of metric is made - based on the above principles or a reading of the INDCs - the assessment and comparison of mitigation effort can draw from a rich array of tools. Some of these are quite simple, transparent, and easily replicable. Others are built on sophisticated modeling platforms, and different modeling teams could make different but equally plausible modeling assumptions and thus produce different results.

\section{Comparison of Descriptive Statistics}

Some metrics, such as emission levels, carbon intensity of economic output, and energy prices require compiling raw data, most of which governments already collect and publish. Producing descriptive statistics that permit the straightforward comparison of emission levels or carbon intensity among a set of countries - or changes over time in these measures - could inform stakeholders and policymakers.

Nonetheless, there are three challenges with the use of simple descriptive statistics to characterize and compare mitigation efforts. First, emission levels and carbon intensity may be incomplete measures of mitigation effort. For example, Russia's emissions have fallen substantially below their 1990 levels as a result of economic restructuring, not emission mitigation policies. Second, price metrics - such as energy prices and carbon prices - will require methods and data for aggregation to construct a single, national measure. Such techniques exist, but they do produce further data demands. Third, comparing metrics that include monetary units (such as emissions per unit of GDP or prices) requires consideration of the appropriate exchange rate to convert values into a common currency (see Aldy and Pizer 2015 for more details on these points).

\section{Energy-Economic Models}

Economists have long employed global energy-economic models to estimate the total costs, marginal costs, and emission reductions versus a "business-as-usual" (BAU) scenario (e.g., Weyant and Hill 1999; McKibbin et al. 2011; Tavoni et al. 2015). Given the stakeholder interest in apples-to-apples comparisons of INDCs, an integrated modeling framework that applies internally consistent data and assumptions to produce comparability metrics is preferred to country-specific alternatives. Individual country reporting may be selective and reflect country-specific data, assumptions, and methods that likely hinder cross-country comparisons (although, as noted below, such reporting is a critical input and starting point for assessments of effort). The UNFCCC track record through the national communications 
processes illustrates this challenge. ${ }^{10}$ Countries produce measures of mitigation effort using methods consistent with UNFCCC guidelines that are not comparable to those produced by other countries (Thompson 2006a). Self-reported metrics alone will not enable the applesto-apples comparisons that are necessary to understand the impacts of countries' intended contributions.

Since one country's domestic program to implement its INDC can impact the economy, energy sector, and emissions of another country through international trade in goods and energy, assessments of INDCs should account for these cross-border impacts. Global energyeconomic models are well designed to do this. Country-specific assessments of mitigation pledges, whether produced by that country's government or by an independent organization, would likely be incapable of accounting for these energy-price, trade-flow, and investment effects. As a result, such country-specific assessments could produce biased emissions, energyprice, and economic impacts from any given INDC.

\section{Statistical Analyses}

One of the shortcomings of global energy-economic models is their focus on large economies and regional aggregation. They may provide detailed analyses of mitigation effort for the United States, China, the European Union (as a whole), and a few other countries, but they cannot meaningfully characterize the mitigation effort and emission outcomes for most countries that have submitted INDCs. Until model development can address these countries, assessments of mitigation effort can be informed, at least in part, by statistical analysis and forecasting.

As Aldy and Pizer (2015) note, reducing emissions from what they would have been in the absence of a domestic mitigation program and the costs of such emission reductions likely serve as the two most comprehensive metrics for mitigation effort. While the latter requires a full economic model, the former can be analyzed in the context of statistical forecast models. For example, analysts could use existing public domain data to estimate forecast models for emissions as well as emission intensity. The statistical forecast could then be used to assess 
the extent to which an emissions level called for by a contribution differs from the forecast. It could also assess how a carbon intensity contribution differs from the forecast. Moreover, for contributions specified as emission reductions from a forecast business as usual, statistical forecast models could serve as the basis for independent construction of these BAU levels.

A number of economists have employed publicly available data on carbon dioxide emissions from fossil fuel combustion to estimate models to forecast global and national carbon dioxide emissions (Holtz-Eakin and Selden 1995; Schmalensee et al. 1998; Auffhammer and Carson 2008). While such models have performed well in forecasting near-term emissions, relative to estimates from structural energy-economic models (e.g., Auffhammer and Carson's [2008] forecast of China's $\mathrm{CO}_{2}$ emissions based on provincial-level emissions data), there are potential limitations to statistical forecast models. Such models are estimated based on historical data and, as some countries develop, the past may be a poor predictor of future emission trends. Moreover, some forecast models may yield imprecise estimates of future emissions (or emission intensity), and a wide range of emission trajectories could be plausible. Thus, imprecise forecasts would not be that informative to policymakers and negotiators. Finally, the academic literature has a bias toward forecasting fossil-fuel $\mathrm{CO}_{2}$ emissions in part because datasets for many countries over a number of decades exist for this greenhouse gas measure. It may be difficult to forecast estimates of all greenhouse gas emissions given less comprehensive datasets covering a shorter period of time for non-fossil carbon dioxide greenhouse gas emissions.

\section{Table 2: Analytical Tools for Assessing Mitigation Effort}

\begin{tabular}{|l|l|l|l|}
\hline Tool & Application & Advantage(s) & Disadvantage(s)/limitations \\
\hline $\begin{array}{l}\text { Comparison } \\
\text { statistics }\end{array}$ & $\begin{array}{l}\text { Comparison of absolute } \\
\text { parameters (emissions } \\
\text { levels, energy prices, } \\
\text { carbon intensity) }\end{array}$ & $\begin{array}{l}\text { Relatively simple to } \\
\text { execute and understand }\end{array}$ & $\begin{array}{l}\text { Emissions levels can be determined } \\
\text { by factors other than mitigation } \\
\text { policy; price data requires }\end{array}$ \\
\hline $\begin{array}{l}\text { Energy- } \\
\text { Economic }\end{array}$ & $\begin{array}{l}\text { Estimation and } \\
\text { comparison of total } \\
\text { costs, marginal } \\
\text { costs, and emission } \\
\text { reductions versus BAU }\end{array}$ & $\begin{array}{l}\text { Provides a common } \\
\text { basis of comparison of } \\
\text { countries using relative } \\
\text { (BAU) measures of } \\
\text { performance in INDCs }\end{array}$ & $\begin{array}{l}\text { Focused on large economies and } \\
\text { regional aggregation }\end{array}$ \\
\hline $\begin{array}{l}\text { Statistical } \\
\text { Analyses and } \\
\text { forecasting }\end{array}$ & $\begin{array}{l}\text { Estimation of forecasts } \\
\text { of emissions and } \\
\text { emission intensity }\end{array}$ & $\begin{array}{l}\text { Expands comparison } \\
\text { to a larger group of } \\
\text { countries; provides a } \\
\text { baseline for assessing } \\
\text { intended emission } \\
\text { abatement }\end{array}$ & $\begin{array}{l}\text { Imprecise forecasts may not be } \\
\text { informative; past may be a poor } \\
\text { predictor of future for rapidly } \\
\text { developing countries }\end{array}$ \\
\hline
\end{tabular}




\section{Data Needs}

Every approach to assessing and comparing mitigation effort imposes important data needs. As a first step toward a well-designed transparency mechanism, countries could begin planning now for the data collection necessary to assess the outcomes of INDC implementation. In light of the kinds of metrics described above, data protocols could initially focus on emission inventories, energy and carbon prices, and relevant macroeconomic indicators. In addition to this tranche of data to be collected, experts in the energy-economic and statistical modeling communities could also identify the data they would need to calibrate and/or estimate their models. Finally, there may be opportunities to design and implement mitigation policies that permit learning about their efficacy, costs, distributional burdens, and other outcomes. Structuring these policies to produce data and enable statistical identification of causal impacts could substantially improve the knowledge base on mitigation-policy impacts (Aldy 2014a).

\section{INSTITUTIONS FOR APPLYING, TESTING, AND EVALUATING TOOLS: THE ROLE OF TRANSPARENCY}

In the emerging international climate policy architecture, which is characterized by highly heterogeneous mitigation efforts, the development and application of analytical tools, along with means for collecting the data upon which these tools rely, is crucial for assessing the country-level, comparative, and aggregate impacts of those efforts. Such tools, and the associated availability of data, in turn rely on effective transparency and review mechanisms (Aldy 2013, 2014b). This section will assess the institutional context of transparency and review mechanisms. Specifically, it will review the relationship between transparency and the credibility of commitments, transparency models from non-climate multilateral regimes, and lessons we might learn from these models.

\section{Transparency and Credible Commitments}

More than 50 years ago, Thomas Schelling wrote about the economic attributes of negotiations. Signaling the seriousness of commitment is often a precondition for securing an agreement among multiple parties. This can be challenging in some contexts, such as international negotiations, given the significant deference to sovereign national governments and limited tools for coercing a state to take actions beyond what it intends to undertake voluntarily. Schelling suggests that transparency on a party's ex ante pledge and ex post outcome can enhance the credibility of commitments: 
"A potent means of commitment, and sometimes the only means, is the pledge of one's reputation.... But to commit in this fashion publicity is required. Both the initial offer and the final outcome would have to be known; and if secrecy surrounds either point, or if the outcome is inherently not observable, the device is unavailable." (Schelling 1956, 288)

Schelling stresses that agreements may need to be structured on what is observable, even if that is only correlated with the intended objective of the negotiation, in order to ensure that one can observe compliance with the agreement. In addition, Schelling's take on the role of trust in repeated negotiations can inform the structure of climate negotiations, given the dynamic nature of the climate change policy problem:

"What makes many agreements enforceable is only the recognition of future opportunities for agreement that will be eliminated if mutual trust is not created and maintained, and whose value outweighs the momentary gain from cheating in the present instance." (Schelling 1956, 301-302)

The information structure of repeated negotiations is a critical element determining the stability of negotiated coalitions. Keohane (1994) emphasizes the importance of informationproducing institutions to facilitate collaboration among nations. In particular, he notes that "more extensive arrangements for monitoring others' behavior" are required in collaboration games and can promote the reciprocity necessary to secure agreement in such games (Keohane 1994, 20). As Barrett (2003) notes in his discussion of monitoring in international environmental agreements, "transparency is of fundamental importance in a repeated game" (p. 284). Wettestad (2007) also notes the relationship between public information about nations'

Improving information on commitments and outcomes supports informal and formal mechanisms of peer review and peer pressure. performance under an agreement and the trust it builds: "good monitoring and verification of practices in international institutions are important in building trust between and among cooperating parties, and in strengthening wider societal confidence" (p. 975). The legitimacy of the international agreement may rest on the caliber, credibility, and independence of the implementing institutions (Bodansky 2007).

Improving information on commitments and outcomes supports informal and formal mechanisms of peer review and peer pressure (Pagani 2002). Nations may initiate an informal bilateral dialogue with those nations lagging far behind (to pressure them to do more) or demonstrating progressive leadership and accomplishment (to learn how to follow their lead effectively). Such information may also enable comparisons among nations that facilitate peer pressure in the next round of negotiations. 
International institutions for information collection and dissemination can lower the costs of an international agreement. Some international non-governmental organizations have developed the technical capacity to assist governments with monitoring (Hempel 1996). Technical and financial assistance for key elements of capacity building could enable improved monitoring, reporting, and evaluation in developing countries (Keohane 1994). International institutions can formally undertake monitoring that lowers the transaction costs of an agreement (Haas et al. 1993). The information compiled on parties' actions and outcomes does not need to meet the standard of a legal compliance mechanism. Indeed, few nations would subject themselves to such a legal mechanism. Such information may "contain deviance within acceptable levels"” (Klabbers 2007, 1004).

\section{Transparency Models from Other Multilateral Regimes}

Policy surveillance serves as a key element of a broad array of international policy regimes. International organizations undertake regular assessments of domestic policy design, implementation, and outcomes in economic policy, trade policy, energy subsidies, and trade in endangered species, among other areas. These experiences can provide important lessons to inform the design of an effective system of climate policy surveillance. The following subsections provide brief summaries of, and identify lessons from, policy surveillance regimes in a variety of contexts, together with a closing synthesis of international policy surveillance.

\section{International Monetary Fund Article IV Consultations}

The International Monetary Fund (IMF) undertakes annual country-level economic surveillance under so-called Article IV consultations (IMF 2001; Schafer 2006). The IMF supports standards for data dissemination and codes for good policy practice that can enable member countries to provide inputs into the annual surveillance process as well as benefit their design and implementation of economic policy. Such standards provide transparent, timely, and measurable metrics for evaluating policy performance and identifying potential economic vulnerabilities.

An Article IV consultation includes an annual visit by IMF economists and experts to the member country, with interim discussions when necessary. Countries are required to provide information to the IMF to enable the review of their economic environment and relevant economic policies. After a country visit, the IMF expert team compiles a report that serves as the basis for a peer review by the Executive Board, which includes 24 country directors representing member countries or groups of countries. A summary of the Board discussion and the report are typically published, and it is the emerging norm that countries agree to the publication of their full Article IV staff report. Making public these reports enables stakeholders to push for better economic policies in their respective countries and improves 
the quality of the IMF review product by effectively subjecting the reviewers to external assessment (Fischer 1999).

\section{OECD Economic Surveys}

The Organisation for Economic Co-operation and Development (OECD) facilitates peer reviews of member states' economic policies every one to two years (OECD 2003; Schafer 2006). As part of this effort, a team of experts from the OECD Secretariat compiles a draft report of the relevant policies for the country under review. The expert team typically visits the country under review, draws data from a variety of public and private sources, and employs the latest research to evaluate the country's economic policy program. A delegation from the country under review responds to the draft report in a meeting of all OECD member states. At this meeting, two so-called lead examiners are drawn from the membership of the OECD to initiate the discussion of the draft report's findings, the response by the country under review, and the report's recommendations for policy reforms. After these two peer reviewers question the country under review, the entire membership has the opportunity to discuss various elements of economic policy with that country's delegation. The final report reflects this discussion and must secure agreement among all OECD members before it is completed. The policy reviews are then made available to the public.

\section{WTO Trade Policy Review Mechanism}

World Trade Organization (WTO) members are subject to a regular review of their trade policies (Mavroidis 1992). The Trade Policy Review Mechanism involves the preparation of a report by a given member country on its trade policies and a report drafted by a team of experts at the WTO Secretariat. The WTO Trade Policy Review Body provides guidance for country reporting, including a template to structure countries' regular reports to the WTO. In addition, developing countries may solicit technical assistance from the Secretariat in preparation of their trade policy reports. The WTO Secretariat expert team typically visits the country under review and draws from multiple sources - government data, third-party data sources, and data in the public domain - in compiling its assessment of the country's trade policy. The Trade Policy Review Body, comprised of all WTO members, receives the Secretariat's report on the country under review and then hosts a delegation from that country to participate in a meeting to discuss and explain the findings in the report. The final versions of the reports submitted by the country under review and the WTO expert review team are published.

\section{Montreal Protocol Reporting on Ozone-Depleting Substances}

Under the Montreal Protocol and related agreements focused on reducing the production and consumption of ozone-depleting substances (ODS), countries report regularly on such ODS 
outcome data to the United Nations Environment Programme (UNEP). Through March 2012, more than 190 countries have reported their ODS consumption data to UNEP for the year 2010, and more than 180 countries have reported annual ODS consumption for at least the past 15 years. ${ }^{11}$ This enables credible estimation of global ODS consumption, informed assessment of consumption over time both globally and by nation to illustrate performance relative to policy goals, and a public, transparent record to facilitate identification of policy leaders and laggards.

The Montreal Protocol surveillance program has a well-defined process and data standards for reporting, as well as a system of reviews of national policies that has strengthened the monitoring and transparency of the agreement (Hampson 1995). The Montreal Protocol Secretariat analyzes the annual national reports and publishes summary compliance reports before the annual international negotiations under this agreement. In some cases, experts employed data compiled by the World Meteorological Organization's (WMO's) Global Ozone Observing System, established in $1957,{ }^{12}$ to verify the ODS data submitted by individual nations (Wettestad 2007).

\section{G-20 Fossil Fuel Subsidies Agreement Implementation and Review}

In 2009, the leaders of the twenty largest developed and developing nations agreed to "phase out and rationalize over the medium term inefficient fossil fuel subsidies while providing targeted support to the poorest" (G20 Leaders 2009). As part of the G-20 agreement, leaders tasked energy and finance ministers to identify their nation's fossil fuel subsidies, develop a plan for eliminating these subsidies, and report back to leaders by the following year's summit. The leaders established processes of implementation and third-party expert review to enhance the transparency of the agreement (Aldy 2015b).

The G-20 published a summary report of each member's identified fossil fuel subsidies and the plan for eliminating them at the 2010 G-20 meeting in Toronto (G-20 2010). Since then, leaders have continued to task energy and finance ministers to continue their efforts and report back regularly. To complement this self-reporting, the G-20 leaders also tasked four international organizations - the International Energy Agency (IEA), the OECD, the Organization of Petroleum Exporting Countries (OPEC), and the World Bank - to undertake their own, joint assessment of fossil fuel subsidies (IEA et al. 2010). This includes an examination of individual countries' subsidies as well as the aggregate economic, energy, and environmental impacts of the sum of these nations' subsidies. Relying on external experts at established

11 UNEP, ODS Consumption in ODP Tons (2012). http://ozone.unep.org/en/data-reporting.

12 The Global Ozone Observing System was subsumed by the Global Atmosphere Watch Programme of the WMO in 1989. See p. 6 at: http://www.wmo.int/pages/prog/arep/gaw/ozone/documents/gaw-shadoz-ndacc-revised-2007-08-29.pdf. 
and recognized international organizations also mitigates concerns about politicization of the evaluation and verification mechanism and allows for a rapid ramping up of the review process that would not be possible if a new bureaucracy had to be constructed from scratch. A potential limitation of relying on existing international organizations, however, may be the legitimacy of those organizations with incomplete memberships. For example, some developing countries may question analyses and reviews by the IEA, whose membership is comprised of developed nations.

\section{Table 3: Transparency Models from Other Multilateral Regimes}

\begin{tabular}{|l|l|l|}
\hline Organization & Process & Key features \\
\hline International Monetary Fund & Article IV Consultations & $\begin{array}{l}\text { Well-defined guidance on reporting; } \\
\text { participation by selected member } \\
\text { governments (Board members) }\end{array}$ \\
\hline $\begin{array}{l}\text { Organisation for Economic Co- } \\
\text { operation and Development }\end{array}$ & Economic Surveys & $\begin{array}{l}\text { Review by OECD staff experts; } \\
\text { response from member government; } \\
\text { discussion by other members }\end{array}$ \\
\hline WTO & Trade Policy Review Mechanism & $\begin{array}{l}\text { Well-defined guidance on reporting; } \\
\text { peer review by WTO member } \\
\text { governments }\end{array}$ \\
\hline Montreal Protocol & $\begin{array}{l}\text { Reporting on Ozone-Depleting } \\
\text { Substances }\end{array}$ & $\begin{array}{l}\text { Well-defined process and data } \\
\text { standards for reporting, and system of } \\
\text { reviews of national policies }\end{array}$ \\
\hline G-20 & $\begin{array}{l}\text { Fossil Fuel Subsidies Agreement } \\
\text { Implementation and Review }\end{array}$ & $\begin{array}{l}\text { Participation of external (third-party) } \\
\text { reviewing organizations, as well as } \\
\text { member-country governments }\end{array}$ \\
\hline
\end{tabular}

\section{Lessons from Other Multilateral Regimes' Transparency Models}

\section{Produce Credible Information through Transparency Mechanisms}

In many multilateral contexts, parties to the international agreement have delegated transparency, review, and policy surveillance responsibilities to international organizations, which can play important roles by generating "neutral" information (Thompson 2006b). ${ }^{13}$ Chayes et al. $(1998,58)$ note that "it is no coincidence that the regimes with the most impressive compliance experience - ILO, IMF, OECD, GATT - depend upon substantial, well-staffed, and well-functioning international organizations" 
Under IMF Article IV consultations and OECD economic policy reviews, permanent staff experts make in-country visits as part of policy and data reviews (IMF 2001; OECD 2003; Schafer 2006). In implementing the Trade Policy Review Mechanism, an expert team from the WTO Secretariat visits the country under review and draws from multiple sources government data, third-party data sources, public domain data - in compiling its assessment of the country's trade policy (Mavroidis 1992). Even under the Intermediate Range Nuclear Missile Force Treaty, the United States and the Soviet Union provided for on-site inspection and monitoring (Chayes and Chayes 1991). An effective transparency mechanism uses collected data and policy information as inputs into the analysis and evaluation of policy actions and outcomes. Analyzing and disseminating data on countries' actions under an agreement are necessary for transparency to contribute to regime compliance (Chayes et al. 1998).

\section{Facilitating Peer Engagement}

Transparency and policy surveillance under the IMF, OECD, and WTO use the expert reviews as key inputs for peer review. For example, in the OECD economic survey process, a delegation from the country under review responds to the draft expert report in a meeting of all OECD members. At this meeting, two lead examiners are drawn from the membership of the OECD to initiate the discussion of the draft report's findings and recommendations for policy reforms. The final published report reflects this discussion and must secure agreement among all OECD members before it is completed. Similar processes operate through the WTO Trade Policy Review Body and the IMF Executive Board (IMF 2001; Schafer 2006).

Providing a forum for member states to engage one another through peer review can facilitate learning about effective policy practice and promote understanding about countries' individual policy design and implementation. In implementing the agreement to eliminate fossil fuel subsidies, the G-20 countries have recently initiated their own peer review process (Aldy 2015b). These peer review processes - under the OECD, the IMF, and the G-20 - serve as a facilitative process, not as a compliance mechanism, and thus enable more candid dialogue among participants. Schelling (2002) describes the effectiveness of "reciprocal multilateral scrutiny" among government negotiating teams in the talks on the allocation of Marshall Plan resources after World War II. This can serve as an important venue for persuasion to enhance ambition through a pledge and review approach to commitments.

Providing a forum for member states to engage one another through peer review can facilitate learning about effective policy practice and promote understanding about countries' individual policy design and implementation. 


\section{Best Policy Practice}

Levy et al. (1993, 415) note that international policy surveillance institutions can "foster capacity-building by providing policy-relevant information in a form that is readily usable." The UNFCCC has adopted Intergovernmental Panel on Climate Change (IPCC) guidelines for emission inventories and land use, land-use change, and forestry (IPCC 2003). Best practices should extend beyond emission accounting to include policies. Aldy (2013) notes that identifying best practice policies through the experiences of countries undertaking emission mitigation can provide important information for developing countries as they design their mitigation programs. The OECD in its economic surveys and the IMF in its Article IV consultations highlight good policy practice in the country under review, and also identify opportunities for countries to pursue best policy practice to address current economic issues in that country.

Developed and emerging economies have substantial experience in implementing policies that can affect investment in low-carbon technologies. Drawing lessons from these successes and failures can inform the design of new policies in all countries, but especially those in developing countries that may lack the institutional capacity to fully evaluate policy options (Levi 2009).

Establishing a set of best practice policies can draw from past efforts to promote the deployment of low-carbon technologies,

The global climate policy architecture could publicize best policy practices through a variety of outlets. and tailor guidance to countries' specific economic and cultural circumstances. As some developing countries become expert on adaptation, they can export best adaptation practices.

The global climate policy architecture could publicize best policy practices through a variety of outlets. First, the regular reviews of individual countries' climate policy programs could include recommendations of policies appropriate to the geographic, cultural, and economic context of that country. Second, best policy practices could be highlighted in annual aggregate surveillance reports. This would need to be more substantive than the current synthesis of industrialized countries' national reports, which is little more than a descriptive summary of information presented in national reports.

\section{Building Capacity in Developing Countries}

The IMF supports standards for data dissemination and codes for good policy practice that facilitate annual surveillance and benefit member countries in their implementation of economic policy. Such standards provide transparent, timely, and measurable metrics for evaluating policy performance and identifying potential economic vulnerabilities. Implementing these standards has "enhance[d] the technical and professional capacities of 
finance ministries and central banks" (Chayes et al. 1998, 53). Developing countries may solicit technical assistance from the WTO Secretariat in preparation of trade policy reports. The World Health Organization, Food and Agriculture Organization, and World Meteorological Organization provide technical assistance to developing countries as a primary programmatic activity (Chayes et al. 1998).

The Secretariat to the Montreal Protocol on Ozone Depleting Substances (ODS) facilitated developing-country reporting by elaborating procedures for tracking and reporting ODS data, providing data-reporting templates, and explaining ways to improve domestic monitoring. The Montreal Protocol increased the costs for failing to submit adequate ODS data reports by linking access to financing for projects to reduce ODS consumption to satisfying the reporting requirements (Wettestad 2007). Conditioning financing from the IMF on the adoption of and adherence to standards and codes of practice could improve the quality of its surveillance regime (Fischer 1999).

International institutions that perform the functions of information collection and dissemination can lower the costs of an international agreement. Technical and financial assistance for key elements of capacity building could enable improved monitoring, reporting, and evaluation in developing countries (Keohane 1994). International institutions can formally undertake monitoring that lowers the transaction costs of an agreement. The provision of standards and reporting templates can improve the transparency of the reporting and review mechanism and enhance surveillance effectiveness. A robust international system of transparency will require improving the technical capacity in many countries to adequately monitor and report their climate policy activities (MacFaul 2006).

\section{Transparency and Role for Civil Society}

Shining a light on policy implementation and outcomes can empower stakeholders and members of civil society. For example, making public Article IV consultations enables stakeholders to push for better economic policies in their respective countries and improves the quality of the IMF review product by subjecting the reviewers to external assessment (Fischer 1999). Requiring transparency and permitting civil society scrutiny can enhance the accountability of an international agreement (Keohane 1998). Non-governmental organizations have provided information to challenge claims made by some countries in the reporting of their human rights policies and practices (Chayes et al. 1998). The Convention on International Trade in Endangered Species (CITES) formally relies on international nongovernmental organizations - the World Conservation Union and the World Wildlife Fund to provide independent reviews of national reports and a trade-monitoring network (Wettestad 2007). Individual counties have increased transparency by making data available, such as the public dissemination of satellite data on Amazonian forest cover by the government of Brazil. 
Public dissemination of emissions data and policy evaluation can enable non-governmental organizations to contribute more effectively to domestic policy design and international negotiations.

\section{USING MITIGATION ASSESSMENTS TO SUPPORT AN INTERNATIONAL AGREEMENT}

\section{Transparency Raises Costs of Deviating from Pledges}

Public information about a nation's actions can empower its leaders and stakeholders to call on and pressure that nation to deliver on its commitments. Political leaders who push for their nations to take on more ambitious climate change risk-reduction policies could benefit from an institution collecting and publicizing information

Producing a common understanding of how disparate pledges that national governments have contributed to the current international process compare to one another can build confidence among countries.

on their actions. By providing an independent assessment of a country's effort and a comparison with the effort of its peers, regular surveillance can legitimize domestic policies (Francois 2001). Such public information also increases the costs to political leaders of failing to deliver on commitments, opening them up to domestic stakeholder pressure and peer pressure from other leaders. Given that emission mitigation pledges are "nationally determined" in the ongoing negotiations, and given that the heterogeneity in INDCs reflects the tailoring of pledges to national circumstances, national leaders have more "political ownership" of their countries' pledges than would be the case in a Kyoto-style framework in which emission targets are an outcome of multilateral negotiations. This political ownership further raises the costs to leaders if their countries' mitigation outcomes do not square with their pledged contributions.

\section{Comparability of Efforts}

Producing a common understanding of how disparate pledges that national governments have contributed to the current international process compare to one another can build confidence among countries. Similar efforts among similar countries would be perceived by many as constituting a "fair" deal. Countries are much more likely to deliver on their current pledges and increase future ambition if they believe they are participating in a fair deal (Ostrom 1998; Barrett 2003; Cazorla and Toman 2001). Moreover, comparable mitigation costs would reflect a cost-effective agreement and address the concerns of energy-intensive industries by leveling the international playing field (e.g. Aldy et al. 2010). As noted above, understanding 
the comparability of effort is a function of domestic politics in many countries, coming from environmental advocates who believe that such assessments can drive more ambition as well as business leaders concerned about the potential adverse competitiveness impacts of domestic mitigation policies.

Understanding comparability of effort can leverage reciprocal mitigation actions. For example, at the 2009 Copenhagen Conference, the European Union and Japan each announced its intent to set more ambitious domestic emission targets if other developed countries committed to comparable reductions. ${ }^{14}$ Such reciprocity has been key to successful international trade negotiations. For example, Finger et al. $(1999,7)$ conclude that "a sense of fairness, of appropriate contribution, was an important concept" in the success of the Uruguay Round of trade talks. Simmons $(1998,87)$ notes that compliance with international agreements is likely better under rules "prescribing reciprocal rather than uni-obligational behavior." Ostrom $(1998,10)$ focuses on the importance of norms in guiding individual efforts toward collective action, emphasizing that "all reciprocity norms share the common ingredients that individuals tend to react to the positive actions of others with positive responses and the negative actions of others with negative responses."

\section{Implications for Border Tax Adjustments}

Some countries have discussed publicly the prospect of implementing border tax adjustments - fees reflecting the carbon content of imported goods - as a part of their domestic mitigation programs. Border tax adjustments are intended to address the emission leakage from one country because it imposes higher mitigation costs on domestic energy-intensive, tradeexposed manufacturing than its trade competitors. Thus, an assessment of the comparability of effort, with specific focus on the marginal costs of mitigating emissions, would serve to identify potential competitiveness effects. This would highlight how trade channels coupled with differences in domestic mitigation ambition could undermine the environmental benefits of the domestic mitigation program in the more ambitious country. It could also spur political support for a border tax on the carbon content of imports from the less ambitious (or nonparticipating) countries (and possibly political opposition to the domestic mitigation program on the basis that it is unfair to domestic manufacturing).

In the absence of independent or formal multilateral assessments and comparability of mitigation effort, individual countries considering border tax adjustments may do this on their own. The 2009 Waxman-Markey bill, which would have established an economy-wide cap-and-trade system in the United States, provides an example. Section 767 of the bill would have provided for a presidential review and determination of the industries and countries that

14 http://unfccc.int/resource/docs/2011/sb/eng/inf01r01.pdf. 
The characteristics of climate

change - reflecting the long-

lived accumulation of greenhouse

gases in the atmosphere - and

of the technologies responsible

for greenhouse gas emissions...

would have been covered by the International Reserve Allowance Program, a de facto border tax adjustment. ${ }^{15}$

highlight the need for a long-term, durable climate change policy.

Institutionalizing the assessment and comparison of effort through multilateral climate transparency may deliver two potential benefits with respect to a border tax adjustment. First, a multilateral transparency mechanism could provide more credible and legitimate assessments of various countries' mitigation efforts. This would enable a facilitative process among countries that could promote understanding of respective mitigation efforts and, as necessary, a ramping up of mitigation ambition in order to avoid the need for a border tax. Such a process would also be more likely to withstand a challenge under the WTO.

Second, a border tax could serve as a way to penalize laggard countries that are not implementing meaningful domestic mitigation programs. The threat of a border tax, even if it is not (or rarely) used, could be sufficient to spur countries to implement serious domestic mitigation programs. For example, China's interest in moving forward with a national cap-and-trade program could reflect, in part, concerns that if it failed to step forward the United States or other trade partners would consider a border tax adjustment (Aldy 2015).

\section{Living Mitigation Plans}

The characteristics of climate change - reflecting the long-lived accumulation of greenhouse gases in the atmosphere - and of the technologies responsible for greenhouse gas emissions (e.g., long-lived capital in power generation, transportation, manufacturing) highlight the need for a long-term, durable climate change policy. In particular, clear and predictable policy signals can drive investment in technology deployment and research and development as well as behavioral change necessary to alter the long-term development trajectory and associated emissions. A successful climate change policy, however, must also be flexible to adapt to new information, such as learning about the climate system, learning about the efficacy and efficiency of specific policy interventions, and learning about the climate change mitigation actions of other countries.

In the ongoing multilateral climate negotiations, countries have pledged emission mitigation contributions via their INDCs that establish various kinds of goals through 2030. The 10-15 year time horizons for these pledges are within the broader context of a long-term, global

15 Full text of the bill, as passed by the U.S. House of Representatives, is available on the web site of the Center for Climate and Energy Solutions: http://www.c2es.org/docUploads/hr2454_house.pdf. Sec. 767 begins on p. 1116. 
climate change objective to limit warming to no more than $2^{\circ} \mathrm{C}$. In addition to the goals, a number of countries have described the domestic public policies that they intend to implement in order to achieve these goals. These INDCs represent the initial phase of countries' efforts to characterize their plans for mitigating emissions. Let me suggest that the INDCs should serve as the first step in what I will refer to as Living Mitigation Plans.

A Living Mitigation Plan should highlight a country's emission mitigation goal(s), describe its efforts to implement this goal, present the details of its plans for domestic policy surveillance and review, and outline the process by which the country would update implementation policies in response to new information. In contrast to Annex B of the Kyoto Protocol or Appendices I and II of the Copenhagen Accord, which were finalized as part of those negotiations and were not subject to future revision absent an entirely new decision of the UNFCCC member governments, the Living Mitigation Plan would be a collection of documents, information, data, and analyses that each country would continually update over time. Just as the INDC is "nationally determined," all of the elements of the Living Mitigation Plan would also be nationally determined and contributed.

The INDC serves as the initial, framing component of a Living Mitigation Plan. More than 150 countries have tabled their INDCs in the negotiations over the course of 2015. Through this pledging process, the Lima Call for Climate Action notes that countries may submit additional information, including data, analysis, methods, and descriptions of implementation timeframes and planning processes that may promote the transparency and credibility of countries' INDCs. The substantial heterogeneity in the types of information included in the INDCs illustrates the variety of ways in which a country may initiate a Living Mitigation Plan. The key first step common to INDCs is setting an overall emission mitigation goal.

Many INDCs also provide information about the types of data and information necessary for understanding and potentially evaluating a country's goal. This may include the scope of coverage by industry, by activity, or by types of greenhouse gases. This may include details about the methods used to inventory and report emissions. It may include a business-asusual "no-policy" forecast to facilitate interpretation of emission targets specified as emission reductions from this forecast BAU. These all serve as part of the necessary foundation for assessing and comparing countries' mitigation efforts.

While some countries have included preliminary details on the domestic mitigation programs they plan to pursue under their INDCs, a Living Mitigation Plan would provide the means for countries to update the policy descriptions and associated data and analyses. For example, the United States submitted its INDC in March 2015 and then, in August 2015, promulgated the Clean Power Plan, which will lower the U.S. power sector's carbon dioxide emissions by $32 \%$ below 2005 levels by 2030 . To further enhance the credibility of its INDC and increase 
the transparency of its domestic mitigation program, the United States could add to its Living Mitigation Plan the final rule, regulatory impact analysis, and related information. As the United States considers additional public policies to lower greenhouse gas emissions, such as regulating methane emissions associated with oil and gas extraction or extending vehicle fuel economy standards beyond 2025, then the policy details and policy analyses could likewise be submitted as a part of the U.S. Living Mitigation Plan.

To inform domestic policymakers, stakeholders, and their publics, as well as to serve as a potential input into subsequent independent policy surveillance, Living Mitigation Plans could also include the processes and results of retrospective reviews of a country's domestic mitigation program. Effective retrospective review and analysis of specific public policy interventions requires planning before the launch of these policies. Such planning would focus on data collection protocols, identification of empirical methods and tools for evaluating policy performance, and, as necessary and feasible, the design of the policy intervention to enable rigorous statistical evaluation of the public policy (Aldy 2014). Given the iterative nature of climate negotiations and the interest in exploring opportunities for enhancing ambition, such retrospective reviews could take place well before the end of the INDC time horizon and serve as interim progress reports.

Such interim reviews could address environmental performance, as well as other issues important to domestic politics and continued participation in the global agreement. For example, as noted above, businesses in many countries are concerned about adverse competitiveness impacts of domestic emission mitigation policies. Rigorous analyses of competitiveness impacts could inform both the domestic politics and policymakers in other countries as they consider how to move forward with domestic program implementation.

Efforts undertaken for the retrospective review could build on the human and analytic capacity being developed by countries to comply with their biennial reporting requirements under the UNFCCC's International Assessment and Review ${ }^{16}$ and International Consultations and Analysis. ${ }^{17}$ The reporting through these existing mechanisms could evolve to focus on policy efficacy. As a part of this process, countries could identify those policies that they have implemented and evaluated that would merit broader application. In promoting such best policy practice, Living Mitigation Plans could produce important information spillovers from the leading countries in combating climate change to those countries that will be ramping up their emission mitigation ambition over time.

\footnotetext{
16 http://unfccc.int/focus/mitigation/the_multilateral_assessment_process_under_the_iar/items/7549.php.

17 http://unfccc.int/national_reports/non-annex_i_natcom/cge/items/8621.php.
} 
In some cases, a country may make a good-faith effort but find that its domestic mitigation policies are failing to deliver on its intended contribution. The Living Mitigation Plan could also provide a mechanism through which countries could identify and communicate the challenges to its mitigation efforts. For example, the Fukushima nuclear disaster in Japan forced a fundamental reconsideration of the future of nuclear power in Japan. In the near term, it also prompted the government to shut down the existing nuclear power-plant fleet for safety inspections and policy review. To meet its energy needs, Japan consumed more oil and natural gas than it had planned to do. Through a Living Mitigation Plan, Japan could document how the shock to its energy system affected near-term and longer-term emissions. In the event that another country encounters an unexpected adverse emissions-related shock, it could highlight how the shock affected its ability to meet its INDC, which could provide transparency that helps enhance credibility even if a country does not realize its emissions mitigation goal.

Given the global nature of energy markets and economic activity more generally, a Living Mitigation Plan could also provide an opportunity for a country to describe both implicit spillovers and explicit linkage of domestic mitigation programs. The implicit spillovers could address the economic interactions among trade partners that undertake emission mitigation policies. Such spillovers could include how domestic mitigation programs may affect the global prices of fossil fuels, or the costs and availability of low-carbon technologies in international trade, or overall economic growth in trade-partner countries. Indeed, the economic costs of any given domestic mitigation program are likely to be affected by mitigation activities in other countries. Emission outcomes for countries that have less than complete coverage of their economies' emissions in their INDCs, or have INDCs specified as a ratio of emissions to GDP are also likely to be affected by the mitigation programs in other countries. Understanding and illustrating these spillovers could serve to inform the ongoing negotiations.

Of course, some spillovers are quite explicit decisions to engage in emission trading - either at the nation-state level or among firms through linked domestic mitigation programs. Living Mitigation Plans could provide regular updates on linked mitigation programs, transfers of emissions allowances, and reviews of the efficacy and environmental integrity of the linked regimes. Since some countries explicitly include trading in their INDCs as a part of their implementation plan (e.g., Switzerland, the European Union), accounting of trading would be an important element of the transparency and legitimacy of the voluntary pledging approach to emissions mitigation. The next section addresses assessment, comparability, and linking of domestic mitigation programs in more detail.

In sum, the Living Mitigation Plan would include a country's emission mitigation goal, description of domestic implementation, interim progress reports and retrospective evaluations, frequent updates on emissions inventories, updates on emission forecasts, details 
on the financing of and results of supported mitigation activities, and related information. This would significantly reduce the burden of conducting independent policy surveillance, enable stakeholders to conduct their own

A Living Mitigation Plan - by providing a means for collecting information on domestic policy implementation and evaluation - aims to strengthen the links between the emission pledge and the review of that pledge. independent assessments, and facilitate the comparison of mitigation efforts among countries.

To ensure easy, broad access to the Living Mitigation Plans, the UNFCCC could supplement the web site for posting mitigation contributions, proposed in the draft agreement to be considered at the Paris conference, ${ }^{18}$ by including these materials. This would involve a substantial redesign of the INDC portal, since it would require much more than a single link to an INDC for each country. Nonetheless, it could build on the existing online presence for INDC submissions.

A Living Mitigation Plan - by providing a means for collecting information on domestic policy implementation and evaluation - aims to strengthen the links between the emission pledge and the review of that pledge. By establishing a close relationship between mitigation pledging and transparency, the process of developing, communicating, and understanding information about a country's current pledge can better inform consideration of future pledges. Moreover, with many developing countries making a two-pronged mitigation pledge, the first part consisting of unsupported mitigation action and the second part supported by external financing, the Living Mitigation Plan can highlight the relationships among mitigation, finance, and transparency more generally. To facilitate the transparency of climate finance - in terms of financial flows and the returns on those financial transfers - developing countries could undertake initial reporting through their Living Mitigation Plans and donors could submit information about their recipient-specific financing for clean energy and related mitigation investments to those developing countries' Living Mitigation Plan online portals.

The self-reporting of mitigation activities through a Living Mitigation Plan is not, however, a substitute for an independent assessment of the impacts of a country's domestic mitigation program. Such an independent assessment will be important in promoting confidence in the pledge and review system. Given the challenge of securing agreement on a robust transparency regime in the UNFCCC negotiations, the review and assessment of countries' mitigation efforts may need to be undertaken by academics, stakeholders, and other analysts in an 
informal manner (Aldy, Pizer, and Akimoto 2015; Sabel and Victor 2015). This provides an opportunity to experiment with tools and processes for review that could eventually feed into a formal multilateral transparency mechanism.

\section{USING MITIGATION ASSESSMENTS TO FACILITATE LINKAGE}

\section{Decision to Link}

An important practical use of assessments and comparisons of mitigation effort is to help individual jurisdictions link trading systems or explicitly coordinate carbon taxes or other policies. The heterogeneity in the mitigation pledges presented in the INDCs is matched by substantial heterogeneity in domestic mitigation policies. The design and implementation of domestic policies will have important implications for potential linking among countries.

In the simple case of two countries considering whether to link their respective cap-and-trade programs, understanding carbon prices with and without linkage would be an informative metric. Absent similar carbon prices under autarky (i.e., economic independence or selfsufficiency), linking two trading systems will lead to significant flows of allowances in one direction and payments in the other. To the extent this kind of exchange is palatable, it may make sense. For example, a rich country might be willing to be a significant net buyer of allowances from a poor country. Or, a small country might be willing to be a net buyer in exchange for the improved liquidity that arises from linking to a larger market. In other situations, significant price differences and the implied trade flows would be a sign of imbalance and may elicit political opposition (Bodansky et al. 2014).

Similarly, the explicit nature of the carbon price in a carbon tax regime suggests that efforts to harmonize carbon prices will need to explicitly tackle why those prices might deviate. Perhaps some countries are expected to lead (based, say, on per capita income). Perhaps there is a recognition of an unequal starting point, in terms of underlying fossil energy prices or other policies, or to reflect differences in national circumstances.

The decision to link, then, can reflect economic, political, and equity considerations. Differences in the explicit carbon prices in any two countries' domestic mitigation programs - or differences in implicit carbon prices (i.e., shadow price of carbon) between any two programs - highlight opportunities for improving cost-effectiveness through linking. By lowering the total cost of reducing emissions, linking could then enable more ambitious mitigation efforts over time. 
The politics of linking are ambiguous. Some may oppose linkage because of large implicit trade flows through the import of emission allowances. Others may view linkage as a way to level the carbon-price playing field for energy-intensive manufacturing - in a constructive, coordinated manner, as opposed to how some view the unilateral

...linkage in conjunction with a transparent policysurveillance regime could reduce the political risk for leaders of countries. imposition of border tax adjustments. Moreover, linking may create vested interests in maintaining the domestic mitigation program that could contribute to a long-term commitment to reducing emissions. Finally, linkage in conjunction with a transparent policy-surveillance regime could reduce the political risk for leaders of countries. As noted above, transparency increases the costs to political leaders of failing to deliver on nationally-determined commitments, for which there is more "political ownership" of the pledge by national leaders than would be the case with targets that are an outcome of multilateral negotiations. But then, ownership might be shared again - although among a smaller set of countries - through a linked system in which mitigation effort is somehow pooled. The potential relationship between linking and transfers affects how one may assess the equity implications of linking any pair of domestic mitigation programs. While linking of cap-and-trade programs enables such transfers, simple coordination or harmonization of domestic carbon taxes may not do so.

Regardless of the motivation to link, there would be very little support for linking if it were perceived to undermine the environmental benefits of domestic emission mitigation programs. Indeed, the initial opposition to international emission trading in the Kyoto Protocol by European negotiators reflected, to some degree, the concern that trading - such as the sale of so-called Russian "hot air" (excess) allowances to the United States or other developed countries - would result in higher emissions than would occur under autarky.

Consider two types of potential links. In the first type, two countries implement cap-and-trade programs and have credible systems of emissions monitoring, allowance tracking, enforcement, a hard emissions cap, and other design features. In this situation, there may be little risk that linking two robust cap-and-trade programs would undermine environmental performance. In the second type, suppose that one country has a robust cap-and-trade program, but the other country either (a) has implemented a different policy instrument that may not necessarily cap emissions, or (b) has little experience enforcing environmental regulations. In this latter case, there may be concerns about the environmental consequences of linking. The next sections consider this second case in more detail. 


\section{Mitigation Value}

Assessments of mitigation value could play an important role in this second type of linking if countries consider coordinated implementation of two disparate mitigation policies. This reflects uncertainty about environmental impacts. How should uncertainty in the analysis inform assessments? First, one type of uncertainty reduces the precision but does not necessarily bias the estimate of mitigation effort. For example, uncertainty about a forecast of carbon intensity - due to uncertainty in forecasting economic growth as well as the structure of the economy - can result in an estimated reduction in emissions under such a policy for a given country, or for a given emission source operating under a carbon intensity performance standard, coupled with a characterization of statistical confidence in that estimate. While wide statistical bounds suggest a lack of precision in the forecast, the forecast may nonetheless be unbiased. Absent risk aversion over emission outcomes, potentially imprecise but unbiased estimates of the mitigation value of this policy would not necessarily require specific consideration in the design of linking.

In contrast, a second type of uncertainty could demand the attention of policymakers when creating links among domestic mitigation programs. Suppose that a policymaker assigns a subjective probability to a country's enforcement of its domestic mitigation program. In the case of countries with limited experience implementing and enforcing emission mitigation policies, or with a poor track record of enforcing such policies, other countries may believe that the likely enforcement regime is more likely to result in under compliance than in full (or over) compliance. In many cases, over compliance may not be possible. For example, a firm covered by a domestic cap-and-trade program may reduce emissions below the amount of allowances it holds, but it can then sell unused allowances to another firm (in its own capand-trade program or to a firm in another country if it has linked with the domestic program). A firm covered by a domestic carbon tax is very unlikely to voluntarily pay more than the specified tax rate on its emissions. In the context of this type of problem, we would expect that uncertainty about compliance would yield asymmetric risk (or a bias) with respect to expected emission abatement.

The same kind of reasoning could apply to evaluations of emission reduction credits under the Clean Development Mechanism (CDM). Instead of assuming that all CDM projects are additional, one could instead estimate a probability that a project is non-additional. Alternatively, one could estimate how a CDM project affects non-project emissions (i.e., an additional wind project that displaces a coal-fired power plant may result in lower coal prices that induce an investment elsewhere in a new coal-fired power plant that would not have occurred in the absence of the wind CDM project). In either case, the risk is asymmetric - it is unlikely that an additional CDM project delivers emission reductions in excess of what is assumed on the premise that it is truly additional - and thus expected emissions are likely lower than emissions assumed under certainty. 
In this case, linking could still occur subject to policy design to address this asymmetric risk of less-thanexpected emission reductions by potential sellers of allowances (or some form of emission reduction credits). The review of a domestic program could produce estimates of emission mitigation value that could inform the linking agreement. For ...exchange rates could serve as a clear signal to those facing adverse rates that they would need to undertake efforts to improve the environmental performance of their domestic mitigation program... example, exchange rates could be established that would reflect the differences in expected mitigation value (Metcalf and Weisbach 2012; Lazarus et al. 2015). If calibrated properly to the probabilities of environmental outcomes - which places demands on the transparency mechanism, as discussed below - then these exchange rates would ensure that trading under the linked arrangement would not result in lower environmental benefits than autarky.

Moreover, exchange rates could serve as a clear signal to those facing adverse rates that they would need to undertake efforts to improve the environmental performance of their domestic mitigation program in order to realize an appreciation in their exchange rate. In this sense, the transparency of the exchange rate and the incentives it creates could drive policy improvements with the intent of moving rates toward parity and, ideally and in the long term, to the point that exchange rates become moot. Alternative means of restricting trading among linked policies could also have similar incentive properties. For example, a fixed quota on the quantity of imported credits from a foreign program or a discount applied to the emission credits from a foreign program could also address some of the concerns about asymmetric risk and encourage the government operating the foreign program to improve the environmental integrity and transparency of its domestic climate policy (Lazarus 2015; Marcu 2015).

Alternatively, the country with the robust domestic mitigation program could agree to only partial linking with the country with the apparently less robust mitigation program. For example, the importing program could limit the number of allowances or emission reduction credits that domestic firms could use for demonstrating compliance with the domestic mitigation program (Metcalf and Weisbach 2012). While every imported allowance or credit could potentially represent less than full environmental benefit for the domestic emission reduction that it would displace, the extent of the environmental loss would be constrained by the import limit. In the long term, it may be beneficial nonetheless to create such partial linking in order to create incentives for new countries with limited regulatory enforcement capacity and modest experience in mitigation emissions, to step forward and launch domestic mitigation policies. Over time, these new countries could improve the implementation and enforcement of their domestic programs, which could eventually prompt the importing country to lift its import limit. 
A linking agreement could also include provisions under which one country could dissolve its links to the other program. For example, an agreement could stipulate that if the mitigation value of a country's domestic mitigation program falls below a specified threshold, then other countries can decide to delink from that country. This would create an additional incentive for potential exporters to invest in robust implementation and enforcement of their domestic mitigation programs.

\section{Mitigation Value, Transparency, and Living Mitigation Plans}

Assessing the mitigation value of domestic mitigation programs illustrates further the importance of a rigorous transparency mechanism. It also highlights the role that independent experts could play in assessments of mitigation value, since such independence could lend credibility and legitimacy to the assessments. Given the likelihood that the UNFCCC negotiations fail to deliver a robust transparency and review mechanism in Paris, stakeholders, academics, and international organizations could play a substantial role in performing evaluations of domestic mitigation programs.

Countries interested in or already operating under linked arrangements could establish a norm in their reporting of domestic mitigation programs through Living Mitigation Plans of focusing on the importance of mitigation value. For example, these countries could explicitly address the mitigation value of transferred allowances and/or emission credits in their current or planned linked systems. Moreover, they could emphasize how estimates of mitigation value by other countries would inform their consideration of future links. A country's Living Mitigation Plan could also explain how it plans to account for emission trading through linked systems and related transfers of mitigation effort. This could include discussion of appropriate institutional details, such as emission registries, that could facilitate linking (see Bodansky et al. 2014 for more details).

Living Mitigation Plans could also be designed such that they include more than just selfreported information by governments. For example, a given country's website for its Living Mitigation Plan would include a section for posting information about its domestic mitigation programs, but also separate portals for: (a) other parties to post information, including their own assessments of mitigation value, documentation on exchanges in emission credits or other forms of mitigation effort, and related details; (b) accredited international organizations, which already undertake extensive analyses of countries' emission mitigation, energy, landuse, and related economic policies; and (c) accredited non-governmental organizations and other observers. Compiling information from all of these sources for a given country's domestic mitigation program could lower the costs of a multilateral transparency and policy surveillance mechanism as well as enable independent assessments by interested stakeholders, academics, and other governments. As noted above, in the long term, a formal and substantial 
institutional capacity for reviewing mitigation efforts that feeds into a facilitative peer review process will be necessary to establish confidence in the pledge and review regime. In the interim, Living Mitigation Plans can promote transparency with the aim of realizing some of the benefits of the more formal process.

\section{CONCLUSIONS}

The pledge and review approach to emission mitigation in the evolving international climate policy architecture has the potential to elicit broader participation than previous multilateral climate efforts. Permitting countries to craft their own mitigation contributions increases the likelihood that they can produce a pledge that is consistent with their respective domestic politics, a necessary condition for countries to deliver on any international climate agreement. With submitted INDCs representing intended mitigation contributions by more than 150 countries, the lead-up to Paris already reflects the broadest commitment to reducing emissions in the history of the UN climate negotiations. The real challenge, however, is ensuring that broad participation delivers meaningful and eventually deep emission reductions.

A rigorous transparency and review mechanism can help meet this challenge. Promoting the understanding of countries' emission mitigation intentions, as well as their performance in delivering on past pledges, can build confidence and enhance trust in the multilateral climate regime. This is especially important in light of the considerable heterogeneity that characterizes the emission-mitigation pledges that have already been submitted in the international negotiations. While permitting countries to tailor their contributions to their national circumstances can facilitate broader participation, the transparency of the contributions is important so that all countries participating in the global agreement understand both the aggregate effect of coordination as well as the comparability of mitigation effort among peers and neighbors.

The international community can draw from an array of existing institutional models for transparency and policy surveillance, including models from the International Monetary Fund, the World Trade Organization, the Organisation for Economic Co-operation and Development, among others. The review and analysis of mitigation pledges can likewise draw from an array of statistical and modeling tools to enable both assessments of aggregate effects

as well as comparisons of mitigation efforts. Leaders, their negotiators, and their publics will want to understand how the international climate policy regime is faring in addressing the risks posed by climate change and will likewise want to understand how their contributions stack up relative to those made by their peers.

To facilitate this transparency, countries can treat their INDCs as the first step in what I have termed here "Living Mitigation Plans." These plans could be periodically updated to 
reflect new details on countries' mitigation policies, documentation to account for potential trade or transfers of allowances or mitigation efforts with other countries, as well as data and analysis on the performance of domestic mitigation programs. Living Mitigation Plans could also be designed to permit the contribution of data and analysis by other parties as well as by observers. This foundation could serve as the starting point for a rigorous, independent external review of pledges. Until the UN climate negotiations can reach agreement on such transparency mechanisms, Living Mitigation Plans can serve as inputs in the reviews and analyses that individual governments, stakeholders, academics, international organizations, and others may undertake of specific domestic mitigation programs.

Such reviews could include assessments of mitigation value that may enable broader linking of domestic mitigation programs. Given the heterogeneity in mitigation pledges and the associated heterogeneity in domestic mitigation programs, informed evaluations of mitigation will be necessary for the linking of disparate programs across countries. As transparency and reviews build trust that countries participating in the international climate policy architecture are moving forward together, opportunities for linking will enable them to seek out and exploit the lowest-cost ways of reducing emissions, which can in turn lead to even more ambitious mitigation goals. 



\section{REFERENCES}

Aldy, Joseph E. 2013. Designing a Bretton Woods Institution to Address Global Climate Change. In: Fouquet, Roger, ed. Handbook of Energy and Climate Change. Cheltenham, UK: Edward Elgar. Earlier version accessible online as Harvard Kennedy School Faculty Research Working Paper RWP12-017. May 2012. https:// research.hks.harvard.edu/publications/workingpapers/citation.aspx?PubId=8381.

Aldy, Joseph E. 2014a. Learning from Experience: An Assessment of the Retrospective Reviews of Agency Rules and the Evidence for Improving the Design and Implementation of Regulatory Policy. Report commissioned by the Administrative Conference of the United States. October 17 Draft. https://www.acus.gov/ sites/default/files/documents/Aldy\%2520Retro\%2520Review\%2520Dra $\mathrm{ft} \% 252011-17-2014 . \mathrm{pdf}$

Aldy, Joseph E. 2014b. The Crucial Role of Policy Surveillance in International Climate Policy. Climatic Change 126 (3-4): 279-292. http://dx.doi.org/10.1007/s10584014-1238-5. Earlier version accessible with no subscription as Harvard Project on Climate Agreements Viewpoints. October 2013. http://belfercenter.ksg.harvard.edu/ publication/23548.

Aldy, Joseph E. 2015a. Frameworks for Evaluating Different Policy Approaches to Address the Competitiveness Concerns of Mitigating Greenhouse Gas Emissions. Harvard Kennedy School Working Paper, October 14 Draft.

Aldy, Joseph E. 2015b. Policy Surveillance in the G20 Fossil Fuel Subsidies Agreement: Lessons for Climate Policy. Climatic Change, published online September 28. http://dx.doi.org/10.1007/s10584-015-1505-0. Earlier version accessible with no subscription as Harvard Project on Climate Agreements Discussion Paper 15-70. June 2015. http://belfercenter.ksg.harvard.edu/publication/25462.

Aldy, Joseph E., Alan J. Krupnick, Richard G. Newell, Ian W.H. Parry, and William A. Pizer. 2010. Designing Climate Mitigation Policy. Journal of Economic Literature 48 (4): 903-934. http://dx.doi.org/10.1257/jel.48.4.903.

Aldy, Joseph E. and William A. Pizer. 2014. Comparability of Effort in International Climate Policy. Harvard Project on Climate Agreements Discussion Paper 14-62. January. http://belfercenter.ksg.harvard.edu/publication/23828.

Aldy, Joseph E. and William A. Pizer. 2015. Alternative Metrics for Comparing Domestic Climate Change Mitigation Efforts and the Emerging International Climate Policy Architecture. Review of Environmental Economics and Policy, forthcoming. August 4, 2015 draft accessible online at: https://dash.harvard.edu/handle/1/22808338. 
Aldy, Joseph E., William A. Pizer, and Keigo Akimoto. 2015. Comparing Emissions Mitigation Efforts across Countries. Working Paper, September Draft. Earlier version accessible online as Resources for the Future Discussion Paper 15-32: http://www.rff. $\mathrm{org} /$ research/publications/comparing-emissions-mitigation-efforts-across-countries.

Aldy, Joseph E. and Robert N. Stavins. 2012. Climate Negotiators Create an Opportunity for Scholars. Science 337: 1043-1044. http://dx.doi.org/10.1126/science.1223836.

Auffhammer, Maximilian, and Richard T. Carson. 2008. Forecasting the Path of China's $\mathrm{CO}_{2}$ Emissions using Province-level Information. Journal of Environmental Economics and Management 55 (3): 229-247. http://dx.doi.org/10.1016/j.jeem.2007.10.002.

Barrett, Scott. 2003. Environment and Statecraft: The Strategy of Environmental Treatymaking. Oxford: Oxford University Press.

Bodansky, Daniel. 2007. Legitimacy. In: Bodansky, Daniel, Jutta Brunee, and Ellen Hey, eds. The Oxford Handbook of International Environmental Law, Oxford: Oxford University Press, 704-722. http://dx.doi.org/10.1093/ oxfordhb/9780199552153.013.0030.

Bodansky, Daniel, Seth Hoedl, Gilbert Metcalf, and Robert Stavins. 2014. Facilitating Linkage of Heterogeneous Regional, National, and Sub-National Climate Policies through a Future International Agreement. Harvard Project on Climate Agreements Discussion Paper, November. http://belfercenter.ksg.harvard.edu/publication/24568.

Bosetti, Valentina and Jeffrey Frankel. 2012. Politically Feasible Emission Targets to Attain 460 ppm $\mathrm{CO}_{2}$ Concentrations. Review of Environmental Economics and Policy 6 (1): 86-109. http://dx.doi.org/10.1093/reep/rer022. Earlier version available without subscription as Harvard Project on Climate Agreements Discussion Paper 09-30. September 2009: http://belfercenter.ksg.harvard.edu/publication/19568.

Cazorla, Marina and Michael Toman. 2001. International equity and climate change policy. Climate Change Economics and Policy: An RFF Anthology. Washington: RFF Press.

Chayes, Abram and Antonia Handler Chayes. 1991. Compliance without Enforcement: State Behavior under Regulatory Treaties. Negotiation Journal 7 (3): 311-330. http:// dx.doi.org/10.1111/j.1571-9979.1991.tb00625.x.

Chayes, Abram, Antonia Handler Chayes, and Ronald B. Mitchell. 1998. Managing Compliance: A Comparative Perspective. In: Edith Brown Weiss and Harold Jacobson, eds. Engaging Countries: Compliance with International Environmental Accords. Cambridge: MIT Press. 
den Elzen, Michel G.J., et al. 2006. Multi-Stage: A Rule-based Evolution of Future Commitments under the Climate Change Convention. International Environmental Agreements: Politics, Law and Economics 6 (1): 1-28. http://dx.doi.org/10.1007/ s10784-004-5645-3.

Finger, J. Michael, Ulrich Reincke, and Adriana Castro. 1999. Market Access Bargaining in the Uruguay Round: Rigid or Relaxed Reciprocity? World Bank Policy Research Working Paper 2258. http://dx.doi.org/10.1596/1813-9450-2258.

Fischer, Stanley. 1999. Reforming the International Financial System. The Economic Journal 109: F557-F576. http://dx.doi.org/10.1111/1468-0297.00472.

Francois, Joseph F. 2001. Trade Policy Transparency and Investor Confidence: Some Implications for an Effective Trade Policy Review Mechanism. Review of International Economics 9 (2): 303-316. http://dx.doi.org/10.1111/1467-9396.00280.

G-20 Leaders Declaration. 2009. Pittsburgh, Pennsylvania, USA, September 25. https:// g20.org/wp-content/uploads/2014/12/Pittsburgh_Declaration_0.pdf.

G-20. 2010. Annex: G-20 Initiative on Rationalizing and Phasing Out Inefficient Fossil Fuel Subsidies. Prepared for the Toronto G-20 Leaders Summit. http://www.eenews. net/assets/2010/06/28/document_cw_03.pdf.

Gupta, Joyeeta. 2007. Beyond Graduation and Deepening: Toward Cosmopolitan Scholarship. In: Joseph E. Aldy and Robert N. Stavins, eds., Architectures for Agreement: Addressing Global Climate Change in the Post-Kyoto World. Cambridge: Cambridge University Press.

Haas, Peter R., Robert O. Keohane, and Marc A. Levy, eds. 1993. Institutions for the Earth: Sources of Effective International Environmental Protection. Cambridge: MIT Press.

Hafner-Burton, Emilie M., David G. Victor, and Yonatan Lupu. 2012. Political Science Research on International Law: The State of the Field. American Journal of International Law 106: 47-97. http://dx.doi.org/10.5305/amerjintelaw.106.1.0047.

Hampson, Fen Osler. 1995. Multilateral Negotiations: Lessons from Arms Control, Trade, and the Environment. Baltimore: The Johns Hopkins University Press.

Hempel, Lamont C. 1996. Environmental Governance: The Global Challenge. Washington: Island Press. 
Hof, Andries F., and Michel G.J. den Elzen. 2010. The Effect of Different Historical Emissions Datasets on Emission Targets of the Sectoral Mitigation Approach Triptych. Climate Policy 10 (6): 684-704. http://dx.doi.org/10.3763/cpol.2009.0649.

Holtz-Eakin, Douglas, and Thomas M. Selden. 1995. Stoking the Fires? $\mathrm{CO}_{2}$ Emissions and Economic Growth. Journal of Public Economics 57 (1): 85-101. http://dx.doi. org/10.1016/0047-2727(94)01449-X.

IEA (International Energy Agency), Organisation for Economic Co-operation and Development, and World Bank. 2010. The Scope of Fossil Fuel Subsidies in 2009 and a Roadmap for Phasing out Fossil Fuel Subsidies; Prepared for G-20 Summit, Seoul (Republic of Korea), 11-12 November 2010. www.worldenergyoutlook.org/ media/weowebsite/energysubsidies/second_joint_report.pdf.

IMF (International Monetary Fund). 2001. Annual Report 2001. Washington, DC: IMF.

IPCC (Intergovernmental Panel on Climate Change). 2003. Good Practice Guidance for Land Use, Land-Use Change, and Forestry. IPCC National Greenhouse Gas Inventories Programme, Technical Support Unit. www.ipcc-nggip.iges.or.jp/public/ gpglulucf/gpglulucf.html.

Keohane, Robert O. 1994. Against Hierarchy: An Institutional Approach to International Environmental Protection. In: Complex Cooperation: Institutions and Processes in International Resource Management, Helge Hveem, ed. Oslo: Scandinavian University Press.

Keohane, Robert O. 1998. International Institutions: Can Interdependence Work? Foreign Policy (110): 82-96. http://dx.doi.org/10.2307/1149278.

Klabbers, Jan. 2007. Compliance Procedures. In: Bodansky, Daniel, Jutta Brunee, and Ellen Hey, eds. The Oxford Handbook of International Environmental Law, Oxford: Oxford University Press, 995-1009. http://dx.doi.org/10.1093/ oxfordhb/9780199552153.013.0043.

Lazarus, Michael, Lambert Schneider, Carrie Lee, and Harro van Asselt. 2015. Options and Issues for Restricted Linking of Emissions Trading Systems. International Carbon Action Partnership. September. https://icapcarbonaction.com/component/ attach/? task=download\&id=279.

Levi, Michael A. 2009. Creating a Climate Policy Review Mechanism. Harvard Project on International Climate Agreements Viewpoints. November. http://belfercenter.ksg. harvard.edu/publication/19738. 
Levy, Marc A., Robert O. Keohane, and Peter M. Haas. 1993. Improving the Effectiveness of International Environmental Institutions. In: Haas, Peter R., Robert O. Keohane, and Marc A. Levy, eds. Institutions for the Earth: Sources of Effective International Environmental Protection. Cambridge: MIT Press.

MacFaul, Larry. 2006. Developing the Climate Change Regime: The Role of Verification. In: Rudolf Avenhaus, Nicholas Kyriakopoulos, Michel Richard, and Gotthard Stein, eds. Verifying Treaty Compliance. Springer, 171-209. http://link.springer.com/ chapter/10.1007/3-540-33854-3_9.

Marcu, Andrei. 2014. The Role of Market Mechanisms in a Post-2020 Climate Change Agreement. Centre for European Policy Studies Special Report 87. May 7. http:// www.ceps.eu/publications/role-market-mechanisms-post-2020-climate-changeagreement.

Marcu, Andrei. 2015. Mitigation Value, Networked Carbon Markets and the Paris Climate Change Agreement. World Bank Group. http://pubdocs.worldbank.org/pubdocs/ publicdoc/2015/9/840951442526241099/Mitigation-Value-Networked-CarbonMarkets-and-the-Paris-Climate-Change-Agreement.pdf.

Mavroidis, P.C. 1992. Surveillance Schemes: The GATT's New Trade Policy Review Mechanism. Michigan Journal of International Law 13: 374-414. http://heinonline. org/HOL/Page?handle=hein.journals $/$ mjil13\&g_sent=1 \&id=384.

McKibbin, Warwick J., Adele C. Morris, and Peter J. Wilcoxen. 2011. Comparing Climate Commitments: A Model-Based Analysis of the Copenhagen Accord. Climate Change Economics 2: 79-103. http://dx.doi.org/10.1142/S201000781100022X. Earlier version available without subscription as Harvard Project on Climate Agreements Discussion Paper 10-35. July 2010. http://belfercenter.ksg.harvard.edu/ publication/20223.

Metcalf, Gilbert E. and David Weisbach. 2012. Linking Policies When Tastes Differ: Global Climate Policy in a Heterogeneous World. Review of Environmental Economics and Policy 6 (1): 110-129. http://dx.doi.org/10.1093/reep/rer021. Earlier version available without subscription as Harvard Project on Climate Agreements Discussion Paper 10-38. July 2010. http://belfercenter.ksg.harvard.edu/publication/20264.

Michaelowa, Axel, Sonja Butzengeiger, and Martina Jung. 2005. Graduation and Deepening: An Ambitious Post-2012 Climate Policy Scenario. International Environmental Agreements: Politics, Law and Economics 5 (1): 25-46. http://dx.doi. org/10.1007/s10784-004-3674-6. 
OECD (Organisation for Economic Co-operation and Development). 2003. Peer Review: An OECD Tool for Co-operation and Change. OECD Policy Brief. December. http://www.keepeek.com/Digital-Asset-Management/oecd/economics/peerreview_9789264099210-en-fr.

Pagani, Fabrizio. 2002. Peer Review: A Tool for Co-operation and Change - An Analysis of an OECD Working Method. Report SG/LEG(2002)1. September 11. Paris: OECD. www.oecd.org/investment/anti-bribery/anti-briberyconvention/1955285.pdf.

Ostrom, Elinor. 1998. A Behavioral Approach to the Rational Choice Theory of Collective Action: Presidential Address. American Political Science Review 92 (1): 1-22. http:// dx.doi.org/10.2307/2585925.

Ranson, Matthew and Robert N. Stavins. 2013. Linkage of Greenhouse Gas Emissions Trading Systems: Learning from Experience. Chicago Journal of International Law 13(2): 403-438. http://dx.doi.org/10.1080/14693062.2014.997658. Earlier version available without subscription as Harvard Project on Climate Agreements Discussion Paper ES 13-02. http://belfercenter.ksg.harvard.edu/publication/23585.

Sabel, Charles F. and David G. Victor. 2015. Governing Global Problems under Uncertainty: Making Bottom-Up Climate Policy Work. Climatic Change, forthcoming. Earlier version available online at: http://www2.law.columbia.edu/ sabel/papers/Sabel\%20and\%20Victor\%20Climatic\%20Change\%20MAY\%2027.pdf.

Schäfer, Armin. 2006. A New Form of Governance? Comparing the Open Method of Co-ordination to Multilateral Surveillance by the IMF and the OECD. Journal of European Public Policy 13 (1): 70-88. http://dx.doi. org/10.1080/13501760500380742.

Schelling, Thomas C. 1956. An Essay on Bargaining. American Economic Review 46 (3): 281-306. http://www.jstor.org/stable/1805498.

Schelling, Thomas C. 2002. What Makes Greenhouse Sense? Foreign Affairs 81 (3): 2-9. https://www.foreignaffairs.com/articles/2002-05-01/what-makes-greenhouse-sense.

Schmalensee, Richard, Thomas M. Stoker, and Ruth A. Judson. 1998. World Carbon Dioxide Emissions: 1950-2050. Review of Economics and Statistics 80 (1): 15-27. http://www.jstor.org/stable/2646725.

Simmons, Beth A. 1998. Compliance with International Agreements. Annual Review of Political Science 1: 75-93. http://dx.doi.org/10.1146/annurev.polisci.1.1.75. 
Tavoni, Massimo, et al. 2015. Post-2020 Climate Agreements in the Major Economies Assessed in Light of Global Models. Nature Climate Change 5: 116-126. http:// dx.doi.org/10.1038/nclimate2475.

Thompson, Alexander. 2006a. Management under Anarchy: The International Politics of Climate Change. Climatic Change 78: 7-29. http://dx.doi.org/10.1007/s10584-0069090-x.

Thompson, Alexander. 2006b. Screening Power: International Organizations as Informative Agents. In: Hawkins, Darren G., David A. Lake, Daniel L. Nielson, and Michael J. Tierney, eds. Delegation and Agency in International Organizations. Cambridge: Cambridge University Press.

Victor, David G. 2007. Fragmented Carbon Markets and Reluctant Nations: Implications for the Design of Effective Architectures. In: Joseph E. Aldy and Robert N. Stavins, eds., Architectures for Agreement: Addressing Global Climate Change in the Post-Kyoto World. Cambridge: Cambridge University Press.

Wettestad, Jorgen. 2007. Monitoring and Verification. In: Bodansky, Daniel, Jutta Brunee, and Ellen Hey, eds. The Oxford Handbook of International Environmental Law, Oxford: Oxford University Press, 974-994. http://dx.doi.org/10.1093/ oxfordhb/9780199552153.013.0042.

Weyant, John P. and Jennifer Hill. 1999. Introduction and Overview. Energy Journal, Special issue: The Costs of the Kyoto Protocol: A Multi-model Evaluation, vii-xiiv. www. jstor.org/stable/23296903.

World Bank. 2015. Networked Carbon Markets. http://www.worldbank.org/en/topic/ climatechange/brief/globally-networked-carbon-markets. 


\section{Harvard Project on Climate Agreements}

belfercenter.hks.harvard.edu/climate

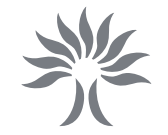

Enel Foundation

Energy for Knowledge

enelfoundation.org

\section{IETA \\ CLIMATE CHALLENGES \\ MARKET SOLUTIONS}

ieta.org

\section{WORLD BANK GROUP}

Climate Change

climatechange.worldbank.org 